\title{
Two new polymorphic structures of alpha-synuclein solved by cryo-electron microscopy
}

Ricardo Guerrero-Ferreira ${ }^{1,10}$, Nicholas M.I. Taylor ${ }^{2}$, Ana-Andrea Arteni ${ }^{3,4}$, Pratibha Kumari $^{5}$, Daniel Mona ${ }^{6}$, Philippe Ringler ${ }^{1}$, Markus Britschgi ${ }^{6}$, Matthias E. Lauer ${ }^{7}$, Ali Makky $^{8}$, Joeri Verasdock ${ }^{5}$, Roland Riek ${ }^{5}$, Ronald Melki ${ }^{4}$, Beat H. Meier ${ }^{5}$, Anja Böckmann, ${ }^{9}$, Luc Bousset ${ }^{4, *}$, and Henning Stahlberg ${ }^{1, *}$

1 Center for Cellular Imaging and NanoAnalytics (C-CINA), Biozentrum, University of Basel, Mattenstrasse 26, 4058 Basel, Switzerland.

2 Structural Biology of Molecular Machines Group, Protein Structure \& Function Programme, Novo Nordisk Foundation Center for Protein Research, Faculty of Health and Medical Sciences, University of Copenhagen, Blegdamsvej 3B, Copenhagen 2200, Denmark.

3 Institut de Biologie Intégrative de la Cellule (I2BC), CEA, CNRS, Université Paris Sud, Université Paris-Saclay, Gif-sur-Yvette, France

4 Institut Fancois Jacob (MIRCen), CEA and Laboratory of Neurodegenerative Diseases, CNRS, 18 Route du Panorama, 92265 Fontenay-Aux-Roses cedex, France

5 Laboratory of Physical Chemistry, ETH Zurich, 8093 Zurich, Switzerland.

6 Roche Pharma Research and Early Development, Neuroscience and Rare Diseases Discovery and Translational Area/Neuroscience Discovery, Roche Innovation Center Basel, Basel, Switzerland.

7 Roche Pharma Research and Early Development, Chemical Biology, Roche Innovation Center Basel, Basel, Switzerland.

8 Institut Galien Paris-Sud, CNRS, Univ. Paris-Sud, University Paris-Saclay, 92296 Châtenay-Malabry, France

9 Molecular Microbiology and Structural Biochemistry, Labex Ecofect, UMR 5086 CNRS, Université de Lyon, 7 passage du Vercors, 69367 Lyon, France

10 Current address: Robert P. Apkarian Integrated Electron Microscopy Core, Emory University School of Medicine, 1521 Dickey Drive NE, Atlanta, Georgia 30322, USA

*Correspondence to:

Anja Böckmann (a.bockmann@ibcp.fr)

Luc Bousset (luc.bousset@cnrs.fr)

Henning Stahlberg (henning.stahlberg@unibas.ch). 


\begin{abstract}
Intracellular inclusions rich in alpha-synuclein are a hallmark of several neuropathological diseases including Parkinson's disease (PD). We here report two new polymorphic atomic structures of alpha-synuclein fibrils termed polymorphs $2 \mathrm{a}$ and $2 \mathrm{~b}$, at $3.0 \AA$ and $3.4 \AA$ resolution, respectively. These polymorphs show a radically different structure compared to previously reported polymorphs. The new structures have a $10 \mathrm{~nm}$ fibril diameter and are composed of two protofilaments which interact via intermolecular salt-bridges between amino acids K45, E57 (polymorph 2a) or E46 (polymorph 2b). The non-amyloid component (NAC) region of alpha-synuclein is fully buried by previously non-described interactions with the N-terminus. A hydrophobic cleft, the location of familial PD mutation sites, and the nature of the protofilament interface now invite to formulate hypotheses about fibril formation, growth and stability.
\end{abstract}

\title{
Impact statement
}

Two new polymorphic structures of recombinant human alpha-synuclein fibrils show striking differences to previous structures, while familial PD mutation sites remain crucial for protofilament interaction and fibril stability. 


\section{Introduction}

Lewy bodies (LB) and Lewy neurites (LN) are neuropathological hallmarks of Parkinson's disease and other Lewy body disorders. These intracellular neuronal features contain a cytoplasmic enrichment of the protein alpha-synuclein ( $\alpha$-Syn), thereby defining these diseases as synucleinopathies (Spillantini et al., 1998a; Spillantini et al., 1997). Apart from this finding in the postmortem brain, the central role of $\alpha$-Syn in Parkinson's disease (PD) is highlighted by the fact that certain mutations in the $\alpha$-Syn gene (SNCA) cause familial forms of PD and other synucleinopathies (Appel-Cresswell et al., 2013; Kruger et al., 1998; Lesage et al., 2013; Pasanen et al., 2014; Polymeropoulos et al., 1997; Zarranz et al., 2004) and that duplication or triplication of the SNCA gene lead to either a sporadic or early-onset PD, respectively, in affected families (Chartier-Harlin et al., 2004; Flagmeier et al., 2016; Fujioka et al., 2014; Ibanez et al., 2004; Singleton et al., 2003). The $14 \mathrm{kDa}$ protein $\alpha$-Syn is known to readily form fibrils in vitro (Conway et al., 1998; Hashimoto et al., 1998) and induce $\alpha$ Syn inclusions when injected in model animals (Mougenot et al., 2012; Peelaerts et al., 2015).

Shahmoradian et al. have recently investigated the ultrastructure of LBs, using identification by fluorescence light microscopy and then correlative imaging by electron microscopy (CLEM). They found that a slight minority of analyzed LBs contained filamentous or dense proteinaceous structures, while the vast majority of LBs was primarily composed of membrane fragments (Lewis et al., 2019; Shahmoradian et al., 2019). However, even in those cases, LBs had been identified due to their enrichment of $\alpha$-Syn (antibody LB509, recognizing residues 115-122 of $\alpha$-Syn). Moors et al. (Moors et al., 2018) recently studied the ultrastructure of LBs by super-resolution light microscopy, revealing an onion-like distribution of different forms of $\alpha$-Syn in nigral LBs and LNs. Their work suggests LBs to be structured encapsulations of aggregated proteins and lipids. While the structure and building blocks of LBs and the putative involvement of aggregated forms of $\alpha$-Syn in the formation of LBs or in toxicity towards neurons and glia appear to be more complex than previously thought, it is clear that the protein $\alpha$-Syn plays a pivotal role in $\mathrm{PD}$, and therefore in LB formation. The conformational state and impact of $\alpha$-Syn protein may also differ strongly between synucleinopathies. Peng et al. reported $\alpha$-Syn preparations from glial cytoplasmic inclusions from multiple system atrophy patients being much more potent in seeding $\alpha$-Syn aggregation into cell cultures than $\alpha$-Syn preparations than PD patients (Peng et al., 2018). A detailed understanding of the conformational space of structural polymorphs of $\alpha$-Syn is important to move forward the discovery of diagnostic tools and therapeutics for synucleinopathies, including PD.

$\alpha$-Syn protein consists of 140 amino acids. The N-terminus (residues 1-60) is rich in lysine residues and contains KTK lipid-binding motif repeats associated with vesicle binding (George, 2002; George et al., 1995; Perrin et al., 2000). It is also the region which contains all known SNCA familial PD mutations: A30P (Kruger et al., 1998), E46K (Zarranz et al., 2004), H50Q (Appel-Cresswell et al., 2013; Proukakis et al., 2013), G51D (Lesage et al., 2013), A53E (Pasanen et al., 2014), and A53T (Polymeropoulos et al., 1997). The central region (residues 61-95) is the non-amyloid- 3 component (NAC region) (Giasson et al., 2001; Ueda et al., 1993), which is essential for $\alpha$-Syn aggregation (Li et al., 2002). The related protein ß-synuclein (ß-syn) (Jakes et al., 1994; Stefanis, 2012) lacks a stretch of 12 aminoacid residues within the NAC region (residues 71-82) and is unable to form fibrils. 
The highly unstructured C-terminus of $\alpha$-Syn (residues 96-140) can bind calcium and it is populated by negatively charged residues (Li et al., 2007; Post et al., 2018; Vilar et al., 2008). Truncation of this domain may play a role in $\alpha$-Syn pathology by promoting fibril formation (Crowther et al., 1998; Li et al., 2005; Liu et al., 2005; Wang et al., 2016) and being involved in Lewy body formation (Dufty et al., 2007; Mahul-Mellier et al., 2019; Prasad et al., 2012). Inhibition of C-terminal truncation has also been shown to reduce neurodegeneration in a transgenic mouse model of Multiple System Atrophy (MSA) (Bassil et al., 2016).

Amyloid fibrils, even within a single sample, may exhibit heterogeneous conformations, referred to as polymorphism. Different polymorphs can be distinguished based on their diameter, their twist, how many protofilaments form a fibril (Riek, 2017), their behavior under limited proteolysis, their appearance under fiber diffraction (Bousset et al., 2013), or their structure using NMR or cryo- EM (Close et al., 2018; Fandrich et al., 2018; Meier and Böckmann, 2015). The polymorphs can be structurally different at the level of the protofibrils, or in the way the protofilament assemble. Specifically for $\alpha$-Syn fibrils, structural heterogeneity has been observed by solid-state NMR (Bousset et al., 2013; Comellas et al., 2012; Comellas et al., 2011; Gath et al., 2012; Gath et al., 2014a; Gath et al., 2014b; Heise et al., 2005; Lv et al., 2012; Verasdonck et al., 2016; Vilar et al., 2008), quenched hydrogen/deuterium (H/D) exchange data (Vilar et al., 2008) and cryo-EM (Guerrero-Ferreira et al., 2018; Li et al., 2018a; Li et al., 2018b). A detailed understanding of the conformational space that structural polymorphs of $\alpha$-Syn do access is central to not only understand how the same polypeptide chain can fold into different structures, but also to thoroughly characterize material used for in vitro and in vivo experiments.

Our recent work on the structure of recombinant $\alpha$-Syn(1-121), using cryo-electron microscopy (cryo-EM) (Guerrero-Ferreira et al., 2018) and other investigations on full-length $\alpha$-Syn ( $\mathrm{Li}$ et al., 2018a; $\mathrm{Li}$ et al., 2018b) revealed $\alpha$-Syn fibrils in a structure composed of two protofilaments that buried the sites associated with familial PD in the interface region between the two protofilaments. This is here termed $\alpha$-Syn polymorph $1 \mathrm{a}$. Li et al. (Li et al., 2018a) reported an additional polymorph, here termed $\alpha$-Syn polymorph $1 b$, in which the interface between virtually identical protofilaments is different. Previous reports on the structure of $\alpha$-Syn fibrils by micro-electron diffraction (microED; (Rodriguez et al., 2015)) or solid-state NMR (Tuttle et al., 2016) either focused on small peptides, or did not describe the two protofilaments and the interface region.

Currently, no high-resolution structures of patient derived $\alpha$-Syn have been obtained. Previous studies looking at the overall morphology of these types of samples, offered a first glance to fibril variability within a sample and among synucleinopathies. Filaments immunolabeled by $\alpha$-Syn antibodies have been described as straight, unbranched fibrils, with widths of $5 \mathrm{~nm}$ or $10 \mathrm{~nm}$ and with varying patterns of conjugated gold depending on the specific antibody used (Crowther et al., 2000). Filaments extracted from cingulate cortex of patients with Dementia with Lewy Bodies (DLB) were also positive for $\alpha$-Syn immunolabeling and revealed comparable morphologies (Spillantini et al., 1998a). In contrast, filaments extracted from Multiple System Atrophy (MSA) brains exhibited larger diameter spanning from $5 \mathrm{~nm}$ to $18 \mathrm{~nm}$ with two morphologies described by Spillantini et al. (Spillantini et al., 1998b) as "straight" and "twisted".

Here, we report new cryo-EM polymorphic structures of in vitro generated amyloid fibrils of $\alpha$-Syn (denoted polymorphs $2 \mathrm{a}$ and $2 \mathrm{~b}$ ). Our structures reveal remarkable differences to the 
previously solved $\alpha$-Syn polymorphs, and inform new hypotheses to explain the mechanism of and factors involved in in vitro amyloid fibril assembly, the potential role of familial PD mutations on fibril structure, and contribute to our understanding of amyloid fibril polymorphism. 


\section{Results and Discussion}

\section{The structure of $\alpha-S y n$ fibril polymorphs}

Fibrils of recombinant, full-length, human $\alpha$-Syn were prepared using the conditions summarized in Table 1. Preformed fibrils (PFFs) were quick-frozen in holey carbon-coated copper grids and imaged with a Titan Krios electron microscope at $300 \mathrm{kV}$, equipped with a Quantum-LS energy filter. Micrographs were acquired with a K2 Summit direct electron detector, drift-corrected and dose-weighted through the FOCUS interface (Biyani et al., 2017).

Helical image processing of 100'323 fibril segments extracted from 1'143 micrographs, revealed the presence of two distinct fibril polymorphs at the step of 3D classification. These polymorphs, termed $\alpha$-Syn polymorph $2 \mathrm{a}$ and $\alpha$-Syn polymorph $2 \mathrm{~b}$ to distinguish them from the previously described $\alpha$-Syn fibrils ( $\alpha$-Syn polymorphs 1a and 1b (Guerrero-Ferreira et al., 2018; Li et al., 2018a; Li et al., 2018b)), were separately refined, resulting in 3D reconstructions at overall resolutions of $3.1 \AA$ and $3.5 \AA$ respectively (Table 2, Figure 1, Figure 1-figure supplement. 1 and Video 1). The left-twisting handedness of the fibrils was confirmed by AFM imaging, as done previously (Guerrero-Ferreira et al., 2018). The maps show clear side-chain densities and $\beta$-strand separation along the helical axis, and indicate that both fibril types are formed by two protofilaments of approximately $5 \mathrm{~nm}$ diameter, which are composed of distinct rungs of density.

Refined atomic models of the fibril cores indicate that polymorph $2 \mathrm{a}$ and polymorph $2 \mathrm{~b}$ in terms of their local atomic structure share a common protofilament kernel, and which is clearly distinct from the one described previously in polymorphs $1 \mathrm{a}$ and $1 \mathrm{~b}$. However, the packing between the two protofilaments is different. Therefore, $\alpha$-Syn fibrils exhibit assembly polymorphism as defined by Riek (2017) (Riek, 2017) and described in Tau between paired helical filaments (PHFs) and straight filaments (SFs) (Fitzpatrick et al., 2017). In each protofilament of the new $\alpha$-Syn polymorph $2 \mathrm{a}$, successive rungs of $\beta$-strands are related by helical symmetry with a rise of $4.8 \AA$ and a twist of $-0.80^{\circ}$ with the subunits within the two protofilaments packed in the same plane, facing each other (Figure 1D, Figure 1-figure supplement 2C) in two-fold symmetry. Distinctively, the two protofilaments in $\alpha$-Syn polymorph $2 \mathrm{~b}$ are offset by $2.4 \AA$ in height between each other, related by an approximate $2_{1}$ screw symmetry with a twist of $179.55^{\circ}$ (Figure 1E, Figure 1figure supplement 2D). In $\alpha$-Syn polymorph $2 \mathrm{a}$, residue $\mathrm{K} 45$ of one protofilament forms a salt-bridge with residue E57 of the other protofilament, and vice-versa (Figure 1B, Figure 1figure supplement $2 \mathrm{~A}$ ). In $\alpha$-Syn polymorph $2 \mathrm{~b}$, the interaction between protofilaments occurs only through salt-bridges between residues K45 and E46 from adjacent protofilaments (Figure 1C, Figure 1-figure supplement 2B).

For polymorph 2a (PDB ID 6SSX) and polymorph 2b (PDB ID 6SST), each $\alpha$-Syn molecule within a protofilament is composed of eight in-register parallel $\beta$-strands ( $\beta 0-7$; Figure 1A, D and E): residues 16-20 (ß0), 38-44 (ß1), 46-50 (ß2), 52-56 (ß3), 61-66 (ß4), 68-72 (ß5), 76-79 (ß6), and 85-92 (B7). These are separated by either a lysine (L45) between $\beta 1$ and $\beta 2$, glycine residues (i.e., G51 between $\beta 2$ and $\beta 3$, and G67 between $\beta 4$ and $\beta 5$ ) or arches (i.e., E57-K60 between $\beta 3$ and $\beta 4$, G73-T75 between $\beta 5$ and $\beta 6$, and K80-G84 between $\beta 6$ and $\beta 7)$. The NAC region encompasses $\beta$-strands $\beta 4$ to $\beta 7$ and it appears entirely surrounded by densities in our cryo-EM map with $\beta 1$ to $\beta 3$ on one side of the fibril and additional densities on the other side. Minor differences between polymorphs $2 \mathrm{a}$ and $2 \mathrm{~b}$ are observed in the turn between $\beta 3$ and $\beta 4$ (Figure 1D and E, Figure $2 A$ and $\mathbf{C}$ ). 
As described for $\alpha$-Syn polymorph 1a (Guerrero-Ferreira et al., 2018), and also shown in patient-derived Tau filaments (Fitzpatrick et al., 2017), there are considerable changes in the height of the $\alpha$-Syn monomer along the helical axis, with the highest point being $\beta 3$ and the lowest $\beta 4$ (Figure 1D and E).

$\alpha$-Syn fibrils in polymorph $1 \mathrm{a}$ are formed by $\beta$-stands that are arranged in bent $\beta$-arches, running along the length of each protofilament, previously described as a Greek key-like architecture (Guerrero-Ferreira et al., 2018; Li et al., 2018a; Li et al., 2018b; Tuttle et al., 2016). Also, the polymorphs $2 \mathrm{a}$ and $2 \mathrm{~b}$ reported here present bent $\beta$-arch motifs. However, the components and the orientation of $\beta$-strands contributing to the motifs are now radically different. In polymorphs $2 \mathrm{a}$ and $2 \mathrm{~b}$, two bent $\beta$-arches orient back-to-back, one showing a single, and the other showing two bends. The first $\beta$-arch is formed by strands $1 / 6,2 / 5$ and $3 / 4$, with bends located at residues $\mathrm{K} 45 / \mathrm{V} 74$, G51/G67, and the tip formed by K58. The strands interact through mainly hydrophobic, but also polar clusters. The second bent $\beta$-arch shares $\beta$-strands 4,5 and 6 with the first one, and comprises in addition $\beta$-strand 7; again, interactions within the arch are of hydrophobic and polar type. This arch shows only one bend, at residues G67/G84.

The structure shares the extended use of glycine residues to form turns, and the hydrophobic and polar clusters forming the fibril core with other fibril structures (as for instance amyloid$\beta$ (Gremer et al., 2017; Schutz et al., 2015; Walti et al., 2016)), which contribute to protofilament stability, as also previously shown for $\alpha$-Syn polymorph 1a (Guerrero-Ferreira et al., 2018; Li et al., 2018a; Li et al., 2018b).

Similar to $\alpha$-Syn polymorph 1a, hydrophilic clusters are found at the periphery of the fibril (Figure 2). However, in contrast to $\alpha$-Syn polymorph 1a, where the protofilament interface is formed by a hydrophobic steric zipper-geometry, in polymorphs $2 \mathrm{a}$ and $2 \mathrm{~b}$ the interface is formed by salt-bridges.

Interestingly, residue I88 marks the beginning of a hydrophobic area composed of residues A89, A90, A91, F94 and V95, which contribute to the stabilization of an additional betastrand density that is clearly visible in the cryo-EM maps of both polymorphs (Figure 1B and C). We propose that this interacting region corresponds in polymorph $2 \mathrm{a}$ to a hydrophobic stretch formed by residues V16 to E20, and here use for it the term $\beta 0$. This region was previously shown to be an isolated $\beta$-strand identified in the N-terminus of $\alpha$-Syn fibrils by solid-state NMR on equivalent fibril preparations (Bousset et al., 2013; Gath et al., 2014b) (Figure 1-figure supplement 3A). The localization of the stretch can be derived from cross peaks present in NMR 2D PAR (De Paepe et al., 2008) spectra that connect S87 to A17, A18 and A19 (Figure 1-figure supplement 3B). Cross peaks in PAR spectra are indicative of proximities smaller than 6-7 $\AA$ between the spins, as illustrated in Figure 1-figure supplement 3D, which shows other meaningful structural restraints identified. This localizes A17, A18 and A19 in proximity to S87 (Figure 1-figure supplement 3C). The orientation of the N-terminal $\beta 0$-strand is then given by both the absence in the spectra of cross peaks between S87 and V16, as well as clear side chain density fitting K21 in the EM map. Interestingly, no signals were observed in the NMR spectra for residues M1-V15, K21-V37 and V95-A140 in the $\alpha$-Syn fibril structure. These regions correspond precisely to the stretches in our cryo-EM structure for which model building is not possible due to lower resolution, suggesting that these regions are indeed disordered in this polymorph. Also, no 
NMR peak doubling, although present for a subset of resonances (Gath et al., 2014b), was observed for residues at the filament interface, and no distinction could be made between polymorphs $2 \mathrm{a}$ and $2 \mathrm{~b}$, indicating that the structures of the monomers in the polymorphs $2 \mathrm{a}$ and $2 \mathrm{~b}$ are very close to each other. The interruption of the polypeptide chain between strands $\beta 0$ and $\beta 1$ in polymorph $2 \mathrm{a}$ and $2 \mathrm{~b}$, and between $\beta 3$ and $\beta 4$ in polymorph $2 \mathrm{~b}$ due to lack of clear density, is compatible with a connection to the following strands of the same layer or alternatively to the neighboring layer.

For both $\alpha$-Syn polymorph $2 \mathrm{a}$ and $2 \mathrm{~b}$, differences in height within residues of a protofilament reveal a hydrophobic area (Figure 2) akin to the hydrophobic cleft described for $\alpha$-Syn polymorph 1a (Guerrero-Ferreira et al., 2018). It is composed of residues Q62 to V74 (B4-ß35) (Figure 1D and E), and located between $\beta$-strands $\beta 2 / \beta 3$ and $\beta 6 / \beta 7$. These residues correspond to a stretch of exclusively hydrophobic or polar residues, completely devoid of charged amino acids. Consistent with these results and with the concept that the hydrophobic core is essential for assembly, is the finding by El-Agnaf et al. (1998) (El-Agnaf et al., 1998) that, within the NAC region, residues E61-A78 are the amyloidogenic component. The hydrophobic cleft in $\alpha$-Syn polymorphs $2 \mathrm{a}$ and $2 \mathrm{~b}$ contrasts with the one found in $\alpha$-Syn polymorph 1a, where intermolecular interactions involving residues V74-V82 may be the initial binding event responsible for fibril elongation (Guerrero-Ferreira et al., 2018).

Our structural cryo-EM analysis of $\alpha$-Syn fibrils prepared with E46K mutant or phosphorylated and N-terminally acetylated protein shows these also to be composed of two protofilaments and having an overall diameter of $10 \mathrm{~nm}$ (Figure 3). The lower order of these fibrils prevented a separation of the $\alpha$-Syn rungs along the fibril axis, but still allowed discerning the separation of individual $\beta$-sheets. As with polymorphs 1a, 2a and 2b, $\beta$-sheets in $\alpha$-Syn fibrils from E46K mutant, phosphorylated or N-terminally acetylated protein are arranged forming the characteristic bent $\beta$-arch like shape, and an arrangement closely resembling that of polymorph $2 \mathrm{a}$ (Figure 3 ).

\section{Comparison with previous structures}

At first glance, the back-to-back arranged $\beta$-arches of polymorphs $2 \mathrm{a}$ and $2 \mathrm{~b}$ appear similar to that of polymorph 1a, wrongly proposing that a mere protofilament rearrangement defines the difference between them. However, closer inspection and comparison with secondary structure elements identified in previous NMR studies on equivalent fibril preparations (Bousset et al., 2013; Gath et al., 2014b) revealed that polymorphs $2 \mathrm{a}$ and $2 \mathrm{~b}$ radically differ from the construction of polymorphs 1 . Figure 4 shows the backbones of the polymorphs with different color codes for $\mathrm{N}$-terminus, NAC region, and $\mathrm{C}$-terminus, and Figure 4-figure supplement 1 shows each 10 residues in a different color. When compared to polymorphs 1 , the new structures of polymorphs $2 \mathrm{a}$ and $2 \mathrm{~b}$ show an inverted bend of the first $\beta$-arch motif, comprising mainly the black and cyan segments in Figure 4-figure supplement 1. This motif is largely conserved between polymorphs $1 \mathrm{a}$ and $1 \mathrm{~b}$ (Li et al., 2018a) (Figure 4, Figure 4-figure supplement 1 and Video 2), where it forms part of the interfilament interface, once via the black segment in polymorph 1a, and once via the cyan/light green segments in polymorph $1 \mathrm{~b}$. In polymorphs 2 , this $\beta$-arch is formed by an inverted amino-acid sequence: when the two motifs are superimposed, the chain runs from cyan to black in one case, in the other from black to cyan. This inversion profoundly changes the amino acid distribution within the arch between polymorphs 1 and 2 . Also, the $\beta$-arch in polymorph 2 is extended with a second bend followed by a $\beta$-strand region, comprising part of the orange segment largely unobserved in polymorphs 1 . 
In polymorph 1 , the light green chain segment forms, together with parts of the abovedescribed first $\beta$-arch, a second bent $\beta$-arch, completed by the red segment. This motif again exists in polymorphs 2 , but is located on the outside of the first arch, while in polymorph 1a it is located at the inside. Also, the arch is inverted, and the amino acid distribution again differs, as shown by the different arrangement of the colored segments. Polymorph $1 \mathrm{~b}$ is devoid of this motif. A hydrophilic cavity identified in polymorph 1a (located in the bend between the black and light green segments) is also present in polymorphs 2 , but there between the partly disordered pink/orange segments, and the red segment.

The different arrangements result in a radically changed interface between the protofilaments in polymorphs 1 and 2. Unlike the hydrophobic interaction between protofilaments in polymorph $1 \mathrm{a}$ by the black segment, and in $1 \mathrm{~b}$ by the cyan and light green segments, the interface in the new polymorphs $2 \mathrm{a}$ and $2 \mathrm{~b}$ is formed by electrostatic interactions in the green segment, through salt-bridges between residues K45 and E57, or K45 and E46, respectively in $2 \mathrm{a}$ and $2 \mathrm{~b}$ polymorphs (Figure 1-figure supplement 2C and F, Figure 1-figure supplement 3, Figure 4-figure supplement 1).

Furthermore, the presence of an additional $\beta$-strand $\beta 0$ on the periphery of the fibril (in the blue segment) is a remarkable difference between polymorphs 1 and polymorphs 2 . This stretch of residues, V16-E20, forms a hydrophobic steric-zipper geometry with residues S87A91, which are part of 37 , at the end of the amyloidogenic NAC region. In polymorphs $2 \mathrm{a}$ and $2 \mathrm{~b}$, this results in the N-terminus wrapping around the fibril and enclosing the NAC region (cyan, light green and red segments). This buries the serine residue at position 87, a phosphorylation site located within the NAC region, inside this interface. This is in contrast to $\alpha$-Syn polymorph 1a, where approximately 40 residues on both ends of the $\alpha$-Syn fibril are flexible and surround the fibril with a fuzzy coat, leaving part of the NAC region (i.e., K80 to V95, red and magenta segments), including S87, exposed (Figure 1B and C, Figure 4-figure supplement 1B).

\section{Origin of distinct $\alpha$-Syn polymorphs}

Presently, there are four different polymorphs of $\alpha$-Syn fibrils known at atomic resolution, including the structures presented here. They can be classified into two groups with each group having a distinct fold (folds 1 and 2) (i.e., at the protofilament level). Within each group there are two distinct protofilament packings or assembly polymorphisms (polymorphs a and b; Figure 4).

In an attempt to rationalize the origin of the distinct polymorphs, we first concentrate on the distinct folds at the protofilament level. All fold 1 structures (polymorphs 1a and $1 \mathrm{~b}$ ) were grown under buffer conditions comprising either a poly-anion (i.e., phosphate with three negative charges and $\mathrm{N}_{3}{ }^{-}$with having locally two negative charges) or a big chaotropic negative ion (i.e. $\mathrm{Br}^{-}$), while polymorphs $2 \mathrm{a}$ and $2 \mathrm{~b}$ of wildtype $\alpha$-Syn were grown under phosphate-free conditions with the only anion being $\mathrm{Cl}^{-}$(Table 1). Interestingly, there are adjacent to the salt-bridge H50-E57 three lysine residues in polymorph 1a at positions K43, K45 and K58 (the latter from the other protofilament) that are close in space. Between them, Guerrero-Ferreira et al. (2018) observed a density in the cryo-EM map, presumably a phosphate ion of poly-anionic nature that neutralizes the repulsion of the three positive charged residues (Guerrero-Ferreira et al., 2018) (Figure 4). Albeit still of polymorph 1a type, in presence of $\mathrm{N}_{3}{ }^{-}$the structure is distinct in this area with $\mathrm{K} 58$ flipping inward into the 
cavity forming a salt-bridge with E61 attributed to the less poly-anion-like character of $\mathrm{N}_{3}{ }^{-}$ when compared with phosphate. In the presence of the chaotropic $\mathrm{Br}^{-}, \mathrm{K} 58$ is facing more the solvent with a closer distance between H50 and K45 (Figure 4). In the absence of a neutralizing poly-anion in this area of positively charged side chains or $\mathrm{Br}^{-}$exerting its chaotropic property, it is unlikely that polymorph 1 can be obtained, indicating that in the presence of $\mathrm{Cl}^{-}$as the only anion, a distinct polymorph must be formed.

The fibrils of the familial variant E46K (Figure 3) were also grown under phosphate conditions but adopt polymorph $2 \mathrm{a}$ fold. The polymorph 1a fold we obtained for the wildtype 1-121 form, introduces an electrostatic repulsion between K46 and K80, instead of the 46-80 salt-bridge stabilizing this polymorph. The structural features thus provide a rationale how changes corresponding to only a few kcal (or less) in the stability of polymorph 1a (such as absence/presence of phosphate, single point mutation), can lead to the protein adopting an entirely different polymorph. This finding also highlights the postulated flat energy landscape of fibril formation and the conformational promiscuity that comes along with it.

The fact that the polymorphs found both by Li et al. (Li et al., 2018a) and here by us are distinct, further accentuates this remark as they grew under similar conditions (except for the salt composition and additives, see Table 1). While the packing interfaces between polymorphs $1 \mathrm{a}$ and $1 \mathrm{~b}$ are both hydrophobic, they still substantially differ, as in polymorph 1a residues V66-A78 form the interface, and in polymorph 1b residues H50-E57 form the interface (Figure 4). The difference is smaller in the case of polymorphs 2, where the protofilament interactions are of inter-protofilament salt-bridge character but are packed differently. It is evident that the energy differences between the two polymorphs are therefore very minute, but still the structures are distinct.

\section{Familial PD mutation sites in the new $\alpha$-Syn polymorphs}

A series of familial mutations have been identified in families with a history of PD. Based on Fujioka et al. (2014) and Flagmeier et al. (2016) (Flagmeier et al., 2016; Fujioka et al., 2014), these mutations may lead to sporadic PD (A30P, E46K, A53E), early-onset (G51D, A53T) or late-onset (H50Q) forms of Parkinson's disease. The localization of the different sites in the structures is compared in Figure 4-figure supplement 1. Fundamentally different folds between polymorphs 1 and 2 place the familial PD mutation sites into an entirely different environment.

The E46K mutation has been found to promote $\alpha$-Syn phosphorylation in mice (Dettmer et al., 2017), and in neuronal cells it showed to be toxic, with toxicity being enhanced by simultaneously mutating E35 and E61 to lysines (Mbefo et al., 2015). E46 holds a central role in polymorphs $1 \mathrm{a}$ and $2 \mathrm{~b}$. In polymorph $1 \mathrm{a}$, where this motif resides at the beginning of one bent $\beta$-arch, E46 forms a stabilizing salt-bridge with K80. In contrast, in $\alpha$-Syn polymorph $2 \mathrm{~b}$ this residue is part of the protofilament interface, where the K45-E46 saltbridge interface to E46-K45 from the other protofibril appears to be critical to the protofilament interface as these residues are the only interaction point between the protofilaments (Figure 1-figure supplement 2). Thus, protofilament interaction in this polymorph $2 \mathrm{~b}$ manner would be unlikely since the mutation would induce a charge repulsion between lysines K45 and E46K from the two protofilaments. And indeed, the mutant E46K adopts polymorph $2 \mathrm{a}$, which result in two lysines (i.e., K45 and K46) from one protofilament interacting with E57 in the other. Interestingly, the $\alpha$-Syn E46K mutant fibril investigated here by cryo-EM, resulted in protofilament assembly corresponding to $\alpha$-Syn polymorph $2 \mathrm{a}$, 
confirming that the interaction between K45/K46 and E57 can indeed be maintained (Figure 3).

Heterozygous mutations in residues H50, G51, and A53 are associated with familial forms of PD (Appel-Cresswell et al., 2013; Lesage et al., 2013; Pasanen et al., 2014; Polymeropoulos et al., 1997). As we reported previously, in $\alpha$-Syn polymorph 1a, these sites are an integral part of the interface region, contributing to the steric-zipper architecture and fibril stability, so that the mutations G51D, A53E and A53T are not compatible with polymorph 1a (GuerreroFerreira et al., 2018) (Figure 4-figure supplement 1). In contrast, in $\alpha$-Syn polymorph $2 \mathrm{a}$, these residues lie in the cavity formed between the two protofilaments, and in polymorph $2 \mathrm{~b}$ they are surface-exposed where the two protofilaments interact (Figure 3-figure supplement 1). While these mutations are not in direct conflict with the formation of $\alpha$-Syn fibril polymorphs $2 \mathrm{a}$ and $2 \mathrm{~b}$, the structures of fibrils formed with these mutations remain to be determined.

The A30P mutation leads to a form of PD with an age of onset between 54 and 76 years (Flagmeier et al., 2016; Fujioka et al., 2014; Kruger et al., 1998). In our structures of polymorphs $2 \mathrm{a}$ and $2 \mathrm{~b}$, a steric-zipper interface between V16-E20 and I88-A91 causes the $\alpha$ Syn N-terminus to wrap around the NAC region. Under these conditions, residue A30 might be surface-exposed in a defined manner, as it forms part of the fibrillar core in the sense that it is on both sides linked to nearby structured regions. The disordered nature of the region between K21 and G37 results in weak density in the cryo-EM map, and makes accurate model building in this region difficult. Nevertheless, in $\alpha$-Syn polymorph 1a, A30 is not part of the fibril core but instead is found in the disordered region corresponding to residues M1 to V37 (Guerrero-Ferreira et al., 2018).

\section{Post translational modifications (PTMs) and fibrillization in $\alpha$-Syn polymorphs}

Certain post-translational modifications of $\alpha$-Syn associated with neuropathology inhibit the process of $\alpha$-Syn fibril formation in vitro, suggesting that they are late events rather than occurring before protein aggregation (Oueslati et al., 2010). Most of these modifications take place at the C-terminal region (Mahul-Mellier et al., 2019), with the exception of acetylation and ubiquitination, which mostly affect residues in the N-terminal region. Ubiquitination alters mostly N-terminal lysines between residues 1 and 36, with K21, K23, K32 and K34 being the major sites for ubiquitin conjugation (Nonaka et al., 2005). The phosphorylated and acetylated forms determined here fold into polymorph 2a (Figure 3). In this polymorph, the amino-acid stretch, which appears disordered in polymorph 1a fibrils, is more distinct, as the interaction of $\beta$-strand $B 0$ with the fibril core brings the $\mathrm{N}$-terminal region back to the fibril. While the involvement of the N-terminal region has been suggested by NMR for two different polymorphs (Bousset et al., 2013; Gath et al., 2012; Gath et al., 2014a; Gath et al., 2014b), our structure for the first time shows how this N-terminal region that is important in the context of post-translational modifications, can be positioned in the protofilament.

\section{Implications for fibril preparation protocols}

When pre-formed fibrils (PFFs) are to be studied, the protocol used for their preparation is crucial. Conditions used to prepare such samples vary (Table 1). It has been previously shown that $\alpha$-Syn polymorphism may arise when different fibrillization methods are used (Lv et al., 2012; Verasdonck et al., 2016). NMR has shown to be able to distinguish fibrils in polymorphic mixtures in samples, when the monomer fold differs substantially (Bousset et al., 2013; Gath et al., 2012; Gath et al., 2014a; Gath et al., 2014b; Verasdonck et al., 2016). 
Still, NMR could for instance not distinguish between the two assembly polymorphs $2 \mathrm{a}$ and 2b. The here reported fibril polymorphism raises questions regarding the structural consistency of recombinant fibrils generated to study $\alpha$-syn in vitro and calls to investigate the structures resulting from different fibril preparation conditions, or to screen fibril polymorphism in samples prepared by a single preparation protocol, in order to compile a library of $\alpha$-Syn polymorphs to inform studies using PFFs on cell culture or animal models.

Recently, fibrillar aggregates of Tau protein were purified from human postmortem brain from Alzheimer's, Pick's disease, and chronic traumatic encephalopathy patients, showing variations in Tau fibril conformations between diseases (Falcon et al., 2018; Falcon et al., 2019; Fitzpatrick et al., 2017), and these fibrils all differed from the in-vitro generated, heparin-induced tau fibrils (Zhang et al., 2019). However, to our knowledge, purification of $\alpha$-Syn fibrils from human brain of Parkinson's disease patients is more challenging. Existing protocols so far have only been able to produce filamentous material that co-fractionated with numerous contaminants (e.g., lipofuscin, amyloid, etc.), including membranes (Iwatsubo et al., 1996). Light microscopy and electron microscopy approaches to analyze the ultrastructural composition of LBs show location maps by fluorescence or structural features at the nanometer scale (Lewis et al., 2019; Moors et al., 2018; Shahmoradian et al., 2019). But methods to study the presence and polymorph of $\alpha$-Syn fibrils in the diseased human brain and cerebrospinal fluid, and the mechanisms by which $\alpha$-Syn may be causing Parkinson's disease and contribute to progression of the disease, remain to be developed.

\section{Conclusion}

We present here two new structures of $\alpha$-Syn fibril polymorphs (polymorph 2a (PDB ID 6rt0), and polymorph $2 \mathrm{~b}$ (PDB ID 2rtb)). These differ in their protofilament interfaces but are formed by the same protofibril subunit structure, which is distinct from previously described $\alpha$-Syn folds.

Our results describe 3D structures very different from previous work, and demonstrate how $\alpha$-Syn amyloid fibrils can reach different cross- $\beta$ architectures in spite of having the same amino acid sequence. The structural information from the various $\alpha$-Syn polymorphs allowed informed hypotheses on how amyloid fibrils may form and how their formation may be related to pathogenicity. More importantly, these structures add to the knowledge of the conformational space of this protein, which is central for structure-based design of imaging tracers or inhibitors of amyloid formation. In this context, a large scale, in vitro study, investigating the structure of $\alpha$-Syn fibrils produced under different aggregation conditions would prove very informative.

Determination of the structural space of fibril polymorphs, including those of $\alpha$-Syn carrying disease-relevant mutations, and of $\alpha$-Syn states purified from diseased human brain, is pivotal to discover whether and how fibrils might form or could be dissolved, and if and how they may interact with affected neurons and contribute to disease. 


\section{Materials and Methods}

\section{$\alpha-S y n$ expression and purification}

The fibrillary polymorph or WT full length unmodified $\alpha$-Syn polymorph $2 \mathrm{a}$ and $2 \mathrm{~b}$ were assembled from monomeric $\alpha$-Syn expressed and purified as described in (Bousset et al., 2013; Gath et al., 2014b). Briefly recombinant, wild-type $\alpha$-Syn was expressed in E. coli strain BL21(DE3), transformed with the expression vector pET3a (Novagen) encoding wildtype, full-length $\alpha$-Syn. Expression was induced by $0.5 \mathrm{mM}$ IPTG for $2 \mathrm{~h}$, when the bacteria grown in LB medium at $37{ }^{\circ} \mathrm{C}$ had reached an optical density of 1.0 at $660 \mathrm{~nm}$. Soluble, monomeric $\alpha$-Syn was purified from the bacteria lysate as previously described (Ghee et al., 2005). $\alpha$-Syn concentration was determined spectrophotometrically using an extinction coefficient of $5960 \mathrm{M}^{-1} * \mathrm{~cm}^{-1}$ at $280 \mathrm{~nm}$. Pure $\alpha-S y n(0.7 \mathrm{mM})$ in $50 \mathrm{mM}$ Tris- $\mathrm{HCl}, \mathrm{pH} 7.5$, $150 \mathrm{mM} \mathrm{KCl}$ was filtered through sterile $0.22 \mu \mathrm{m}$ filters and stored at $-80{ }^{\circ} \mathrm{C}$.

For preparation of fibrils carrying post-translationally modifications, full-length $\alpha$-Syn was expressed in competent Escherichia coli BL21(DE3) (Stratagene, La Jolla, CA, USA) from the pRT21 expression vector. To acetylate the N-terminus, cells were pre-transfected by pNatB vector coding for the N-terminal acetylase complex (plasmid kindly provided by Daniel Mulvihill, School of Biosciences, University of Kent, Canterbury, UK) (Johnson et al., 2010). The various $\alpha$-Syn forms were purified by periplasmic lysis, ion exchange chromatography, ammonium sulfate precipitation, and gel filtration chromatography as previously described (Guerrero-Ferreira et al., 2018; Huang et al., 2005; Luk et al., 2009). Purified $\alpha$-Syn was phosphorylated using polo like kinase 2 (PLK2) expressed in E. coli BL21-DE3-pLysS, and isolated via its His-tag. Phosphorylated from non-phosphorylated $\alpha-$ Syn was then separated using standard ion exchange and gel filtration chromatography. Nterminally acetylated and phosphorylated $\alpha$-Syn strains were cleared from endotoxins using one run of Detoxi-Gel Endotoxin Removing Gel (Thermo Scientific) or until endotoxins were below detection level. Protein sequences were verified by tryptic digestion and MALDI mass spectrometry (MS). Alternatively, HPLC/ESI tandem MS was performed to determine total mass. Coomassie blue or silver staining of the SDS PAGE gel and analytical ultracentrifugation were used to determine purity and monodispersity. Protein concentration was measured using the bicinchoninic acid (BCA) assay (Thermo Scientific) with bovine serum albumin as a standard. Purified $\alpha$-Syn was dialyzed in a $2 \mathrm{kDa}$ Slide-A-Lyzer unit (Thermo Scientific, for max. $3 \mathrm{ml}$ ) against HPLC-water (VWR). Aliquots $(500 \mu \mathrm{g})$ were dispensed into $1.5 \mathrm{ml}$ tubes, frozen on dry ice, and lyophilized for $2 \mathrm{~h}$ in an Eppendorf concentrator (Eppendorf) and stored at $-80^{\circ} \mathrm{C}$ until use.

Disease-linked E46K mutant $\alpha$-Syn was expressed and purified using a periplasmic purification protocol as described earlier (Campioni et al., 2014; Huang et al., 2005). Briefly, plasmid pRK172 was co-expressed with N-terminal acetyltransferase B (NatB) complex as described earlier (Johnson et al., 2010). Colonies containing both plasmids (NatB and pRK172) were selected using two different antibiotics and grown in 1 liter of lysogeny broth at $37^{\circ} \mathrm{C}$. After reaching an optical density of 1.0 at $600 \mathrm{~nm}$, expression was induced with $1 \mathrm{mM}$ IPTG for $5 \mathrm{~h}$. Cells were harvested and $\alpha$-Syn collected from the periplasmic space of the cells, using osmotic shock methods described earlier (Huang et al., 2005). Protein was further purified using ion exchange chromatography and hydrophobic interaction chromatography (Campioni et al., 2014). 


\section{Fibrillization}

Full-length, wildtype unmodified $\alpha$-Syn was incubated at $37^{\circ} \mathrm{C}$ for one week under continuous shaking in an Eppendorf Thermomixer set at 600 r.p.m., to assemble into fibrillar form. $700 \mu \mathrm{M} \alpha$-Syn was assembled in $50 \mathrm{mM}$ Tris-HCl, $\mathrm{pH}$ 7.5, $150 \mathrm{mM} \mathrm{KCl}$ buffer (Table 1).

To prepare fibrils of full-length, phosphorylated, N-terminally acetylated, N-terminally acetylated and the E46K mutant $\alpha$-Syn, recombinant protein (dialyzed and lyophilized) was diluted to $5 \mathrm{mg} / \mathrm{mL}$ in $200 \mu \mathrm{L}$ of Dulbecco's phosphate buffered saline (DPBS) buffer (Gibco; $2.66 \mathrm{mM} \mathrm{KCL}, 1.47 \mathrm{mM} \mathrm{KH}{ }_{2} \mathrm{PO} 4,137.93 \mathrm{mM} \mathrm{NaCl}, 8.06 \mathrm{mM} \mathrm{Na} 2 \mathrm{HPO}_{4}-7 \mathrm{H}_{2} \mathrm{O} \mathrm{pH}$ 7.0 - 7.3). After 5 days of incubation at $37^{\circ} \mathrm{C}$ with constant agitation $(1,000 \mathrm{rpm})$ in an orbital mixer (Eppendorf), reactions were sonicated for $5 \mathrm{~min}$ in a Branson 2510 water bath, aliquoted, and stored at $-80^{\circ} \mathrm{C}$. All fibrils were created in the presence of an air-water interface. The presence of amyloid fibrils was confirmed by thioflavin $\mathrm{T}$ fluorimetry and high molecular weight assemblies were visualized by gel electrophoresis.

\section{Electron microscopy}

Cryo-EM grids were prepared using a Leica EM GP automatic plunge freezer (Leica Microsystems) with $80 \%$ humidity at $20^{\circ} \mathrm{C} .3 \mu \mathrm{L}$ aliquots were applied onto 60 -second glowdischarged, 300 mesh, copper Quantifoil grids (R2/1). After blotting, grids were plunge frozen in liquid ethane cooled by liquid nitrogen.

Micrographs were acquired on a Titan Krios (ThermoFisher Scientific) transmission electron microscope, operated at $300 \mathrm{kV}$ and equipped with a Gatan Quantum-LS imaging energy filter (GIF, $20 \mathrm{eV}$ zero loss energy window; Gatan Inc.). Images were recorded on a K2 Summit electron counting direct detection camera (Gatan Inc.) in dose fractionation mode (50 frames) using the Serial EM software (Mastronarde, 2005) at pixel sizes of $0.831 \AA$ or 0.629 $\AA$, and a total dose of $\sim 69$ electrons per square Angstrom $\left(\mathrm{e}^{-} / \AA^{2}\right)$ for each micrograph. Micrographs were processed and analyzed during data collection with FOCUS (Biyani et al., 2017), applying drift-correction and dose-weighting using MotionCor2 (Zheng et al., 2017). Specific data collection parameters for the various datasets are detailed in Table 2.

\section{Image processing}

Computer image processing and helical reconstruction was carried out with RELION 2.1 (Scheres, 2012) and RELION 3.0 B (Zivanov et al., 2018), using the methods described in (He and Scheres, 2017). Filament selection per micrograph was done manually in RELION 2.1. Segments were extracted with a box size of 280 pixels and an inter-box distance of 28 pixels. A summary of the number of micrographs and segments that went into the various steps of processing are presented in Table 2. After 2D classification with a regularization value of $\mathrm{T}=2,2 \mathrm{D}$ class averages with a visible separation of individual rungs were selected for further processing. For class averages formed by segments from polymorph 2, the calculated power spectra showed a meridional peak intensity (Bessel order $n=0$ ) at the layer line of $1 /(4.9 \AA)$. For polymorph $2 b$, power spectra showed peak intensities on both sides of the meridian (Bessel order $n=1$ ). This is the result of an approximate 21 screw symmetry between $\alpha$-Syn subunits on the two protofilaments (Figure 1-figure supplement 1 ). The best $2 \mathrm{D}$ classes were selected for a round of $3 \mathrm{D}$ classification with $\mathrm{T}=8$ and optimization of the helical twist and rise using a helical_z_percentage parameter (He and Scheres, 2017) of 10\%. A cylinder generated via the helix toolbox tool was used as initial model. This resulted in 3 classes where $\beta$-sheets perpendicular to the fibril axis were clearly separated. Segments contributing to classes 1 and 2, which corresponded to $\alpha$-Syn polymorphs $2 \mathrm{a}$ and $2 \mathrm{~b}$, 
respectively, were then processed separately. The $3 \mathrm{D}$ maps from their respective classes were used as initial models after applying a low-pass filter to $30 \AA$. Then, a 3D classification with a single class $(\mathrm{K}=1)$ and $\mathrm{T}=20$, which has allowed the successful reconstruction of amyloid filaments, was carried out (Falcon et al., 2018; Fitzpatrick et al., 2017; Guerrero-Ferreira et al., 2018).

The 3D auto-refine procedure in RELION 3.0, with optimization of helical twist and rise, resulted in structures with overall resolutions of $3.34 \AA$ ( $\alpha$-Syn polymorph $2 a)$ and $3.75 \AA(\alpha-$ Syn polymorph $2 b$ ). Post-processing with soft-edge masks and estimated map sharpening $B$ factors of -67.1 and $-76.4 \AA^{2}$, respectively, gave maps with resolutions of $3.0 \AA$ ( $\alpha$-Syn polymorph 2a) and $3.3 \AA$ ( $\alpha$-Syn polymorph $2 \mathrm{~b}$ ) (by the FSC 0.143 criterion). Local resolution values and local-resolution-filtered maps were obtained in RELION 3.0. (Table 2, Figure 1-figure supplement 1)

\section{Model building and refinement}

A model for the $\alpha$-Syn polymorph 2 a fibril was built into the RELION local resolutionfiltered map with COOT (Emsley and Cowtan, 2004), by conserving as many secondary structure elements as possible from our previous $\alpha$-Syn polymorph 1 model (PDB ID 6h6b) (Guerrero-Ferreira et al., 2018), together with the use of secondary structure information derived from ssNMRs served to establish an initial model which served as an initial model. The structure was then refined against the same map with PHENIX real space refine (Afonine et al., 2013) using rotamer and Ramachandran restraints, and non-crystallographic symmetry and beta strand geometry constraints. The building and refinement of the $\alpha$-Syn polymorph $2 \mathrm{~b}$ model was more challenging due to the lower resolution of the map. An initial structure was built into the $\alpha$-Syn polymorph $2 \mathrm{~b}$ local resolution-filtered map by fitting of the $\alpha$-Syn polymorph $2 \mathrm{a}$ model using COOT. To successfully refine the structure, it was necessary to generate secondary structure restraints in Phenix, based on CA backbone and intermolecular beta sheets to refine the structure. All structures were validated using Molprobity (Williams et al., 2018).

\section{NMR spectroscopy}

NMR spectra were recorded at $20.0 \mathrm{~T}$ static magnetic field using $3.2 \mathrm{~mm}$ rotors and a tripleresonance probe. The reproducibility of the sample preparation was previously verified with $20 \mathrm{~ms}$ DARR fingerprint spectra (Gath et al., 2014b). The secondary chemical-shift analysis was based on the sequential assignments (BMRB accession code 18860) and was presented before (Gath et al., 2014a; Gath et al., 2014b). The PAR spectrum (De Paepe et al., 2008; Lewandowski et al., 2007) was recorded using a mixing time of $8 \mathrm{~ms}$. The assignments for the S87/A17-19 cross peaks are unambiguous within a range of $0.15 \mathrm{ppm}$, corresponding to about $1 / 2$ of the ${ }^{13} \mathrm{C}$ line width. Assignments of restraints given for reference on the full aliphatic region of the PAR spectrum in the Figure 1-figure supplement 3 are mostly ambiguous, which prevented structure determination by NMR. Ambiguities were lifted by comparison to the here determined cryo-EM structure.

\section{Data availability}

Raw cryo-EM micrographs are available in EMPIAR, entry numbers EMPIAR-10323. The 3D maps are available in the EMDB, entry numbers EMD-10307 ( $\alpha$-Syn polymorph $2 a)$ and EMD-10305 ( $\alpha$-Syn-polymorph $2 b$ ). Atomic coordinates are available at the PDB with entry numbers PDB 6SSX ( $\alpha$-Syn polymorph $2 a$ ) and PDB 6SST ( $\alpha$-Syn polymorph $2 b$ ). 


\section{Conflict of interest}

D.M., M.E.L., and M.B. are full time employees at Roche and may additionally hold Roche stock/stock options.

R.G.F, N.M.I.T, A.A.A., P.R., A.M., J.V., R.R., J.R., R.R., R.M., B.H.M.; A.B., L.B., H.S. declare no conflict of interest.

\section{Author contribution}

R.G.F Conceptualization, Data curation, Formal analysis, Validation, Investigation, Visualization, Methodology and Writing the manuscript.

N.M.I.T. Validation, visualization, Structural calculation, building of the structural model, contributed to data interpretation, discussion and writing the manuscript.

A.A.A. Screen the assemblies for optimization, optimize cryo-EM freezing conditions and set up experimental conditions for particle imaging. Acquire the first high resolution Cryo-EM images of the "fibril" type of assemblies.

D.M., M.E.L., and M.B. expressed, purified and analyzed recombinant human alphasynuclein (wt, N-acetylated, pSer129 aSyn, C-terminally truncated forms) and performed initial biochemical and biophysical characterization and quality control of generated fibrils. M.E.L. and M.B. contributed to data interpretation and discussion.

P.R. participate to Investigation and contributed to data interpretation and discussion.

A.M. acquire and interpret AFM data on alpha-synuclein.

J.V. acquire and interpret Solid state NMR data.

R.R. expressed, purified and analyzed recombinant human alpha-synuclein (E46K and Nacetylated form) and performed initial biochemical and biophysical characterization and quality control of generated fibrils.

R.M. Conceptualization, Resources, Supervision, Funding acquisition, discussion and Writing the manuscript.

A.B. Conceptualization of solid-state NMR studies, supervision, building of the structural model, Investigation, discussion and writing the manuscript.

B.H.M. Conceptualization of NMR studies, Resources, Supervision, Investigation, contributed to editing the manuscript.

L.B. expressed, purified and analyzed recombinant human alpha-synuclein (wt, unmodified form) generated fibrils. Contributed to data interpretation, building of the structural model and discussion. Writing the original draft.

H.S. Conceptualization, Resources, Supervision, Funding acquisition, Investigation, Methodology, Writing the original draft, Project administration.

\section{Acknowledgements}

We thank Liz Spycher, Jana Ebner, Alexandra Kronenberger, Daniel Schlatter, Daniela Huegin, Ralph Thoma, Christian Miscenic, Martin Siegrist, Sylwia Huber, Arne Rufer, Eric Kusznir, Peter Jakob, Tom Dunkley, Joerg Hoernschmeyer, and Johannes Erny at Roche for their technical support to clone, express, purify and characterize the different forms of $\alpha$-Syn; Kenneth N. Goldie, Lubomir Kovacik and Ariane Fecteau-Lefebvre for support in cryo-EM. Calculations were performed using the high-performance computing (HPC) infrastructure administered by the scientific computing center at the University of Basel (sciCORE; http://scicore.unibas.ch). The Novo Nordisk Foundation Center for Protein Research is supported financially by the Novo Nordisk Foundation (NNF14CC0001). N.M.I.T. is a member of the Integrative Structural Biology Cluster (ISBUC) at the University of 
Copenhagen. This work was in part supported by the Synapsis Foundation Switzerland, the Heidi-Seiler Stiftung Foundation, and the Swiss National Science Foundation (grants CRSII3_154461 and CRSII5_177195 and 20020_178792), and the French ANR (ANR-12BS08-0013-01), the LABEX ECOFECT (ANR-11-LABX-0048) within the Université de Lyon program Investissements d'Avenir (ANR-11-IDEX-0007). A.A.A., L.B. and R.M. received funding from the European Union's Horizon 2020 research and innovation programme under grant agreement No. 116060 (IMPRiND), the Swiss State Secretariat for Education, Research and Innovation (SERI) under contract number 17.00038, the Fondation Bettencourt Schueller, The Fondation pour la Recherche Médicale (Contract DEQ 20160334896), The Fondation Simone et Cino Del Duca of the Institut de France and the EC Joint Program on Neurodegenerative Diseases (TransPathND, ANR-17-JPCD-0002-02 and Protest-70, ANR-17-JPCD-0005-01), by the French Infrastructure for Integrated Structural Biology (FRISBI) [ANR-10-INSB-05-01]. The opinions expressed and arguments employed herein do not necessarily reflect the official views of these funding bodies. 
bioRxiv preprint doi: https://doi.org/10.1101/654582; this version posted November 21, 2019. The copyright holder for this preprint (which was not certified by peer review) is the author/funder, who has granted bioRxiv a license to display the preprint in perpetuity. It is made available under aCC-BY-NC-ND 4.0 International license.

Guerrero-Ferreira et al., Polymorphism in alpha-synuclein fibrils

\section{Tables}

Table 1: Growth conditions for $\alpha$-Syn fibrils

\begin{tabular}{|c|c|c|c|c|c|c|c|c|c|}
\hline Study & Buffer composition & pH & $\begin{array}{l}\text { Temp- } \\
\text { erature }\end{array}$ & Time & $\begin{array}{c}\text { Concen- } \\
\text { tration }\end{array}$ & Method & $\alpha$-Syn type & \begin{tabular}{|c|} 
Poly- \\
morph \\
\end{tabular} & PDB \\
\hline This study & $\begin{array}{c}50 \mathrm{mM} \text { Tris- } \mathrm{HCl} \\
150 \mathrm{mM} \mathrm{KCl}\end{array}$ & 7.5 & $37^{\circ} \mathrm{C}$ & $\begin{array}{l}1 \text { week } \\
(600 \\
\text { r.p.m. }) \\
\end{array}$ & $700 \mu \mathrm{M}$ & $\begin{array}{c}\text { Cryo-EM + } \\
\text { NMR }\end{array}$ & $\begin{array}{l}\text { Full-length } \\
\text { ("named } \\
\text { fibrils") } \\
\end{array}$ & $2 a, 2 b$ & $\begin{array}{c}6 s s x \\
6 s s t\end{array}$ \\
\hline $\begin{array}{c}\text { (Guerrero- } \\
\text { Ferreira et } \\
\text { al., 2018) }\end{array}$ & \begin{tabular}{|c|} 
DPBS (Gibco) \\
$2.66 \mathrm{mM} \mathrm{KCl}$, \\
$1.47 \mathrm{mM} \mathrm{KH} 2 \mathrm{PO} 4$, \\
$137.93 \mathrm{mM} \mathrm{NaCl}$, \\
$8.06 \mathrm{mM} \mathrm{Na} 2 \mathrm{HPO} 4$ \\
\end{tabular} & 7 to 7.3 & $37^{\circ} \mathrm{C}$ & $\begin{array}{l}5 \text { days } \\
(1000 \\
\text { r.p.m. })\end{array}$ & $\begin{array}{c}360 \mu \mathrm{M} \\
(5 \\
\mathrm{mg} / \mathrm{mL})\end{array}$ & Cryo-EM & $\begin{array}{c}\text { Truncated } \\
(1-121)\end{array}$ & 1a & $6 \mathrm{~h} 6 \mathrm{~b}$ \\
\hline $\begin{array}{c}\text { (Li et al., } \\
\text { 2018a) }\end{array}$ & $\begin{array}{c}50 \mathrm{mM} \text { Tris, } 150 \\
\mathrm{mM} \mathrm{KCl} \\
0.05 \% \mathrm{NaN} 3\end{array}$ & 7.5 & $37^{\circ} \mathrm{C}$ & $\begin{array}{l}3 \text { days } \\
(900 \\
\text { r.p.m. })\end{array}$ & $500 \mu \mathrm{M}$ & Cryo-EM & $\begin{array}{l}\text { Full-length, } \\
\text { N-terminal } \\
\text { acetylated }\end{array}$ & $1 \mathrm{a}$ & $6 a 6 b$ \\
\hline $\begin{array}{l}\text { (Li et al., } \\
\text { 2018b) }\end{array}$ & $\begin{array}{c}15 \text { mM tetrabutyl- } \\
\text { phosphonium } \\
\text { bromide }\end{array}$ & $\begin{array}{c}\text { Not } \\
\text { speci- } \\
\text { fied } \\
\end{array}$ & $\begin{array}{c}\text { Room } \\
\text { tempe-- } \\
\text { rature }\end{array}$ & $\begin{array}{l}\text { 14-30 days } \\
\text { (quiescent) }\end{array}$ & $300 \mu \mathrm{M}$ & Cryo-EM & Full-length & $1 \mathrm{a}, \mathrm{b}$ & $\begin{array}{l}6 \mathrm{cu} 7 \\
6 \mathrm{cu} 8\end{array}$ \\
\hline $\begin{array}{c}\text { (Tuttle et al., } \\
\text { 2016) }\end{array}$ & \begin{tabular}{|c|}
$50 \mathrm{mM}$ sodium \\
phosphate \\
$0.12 \mathrm{mM}$ EDTA \\
$0.02 \%$ sodium azide \\
$(\mathrm{w} / \mathrm{v})$ \\
\end{tabular} & 7.4 & $37^{\circ} \mathrm{C}$ & $\begin{array}{l}3 \text { weeks } \\
(200 \\
\text { r.p.m. })\end{array}$ & $\begin{array}{c}1000 \mu \mathrm{M} \\
\quad(15 \\
\mathrm{mg} / \mathrm{mL})\end{array}$ & NMR & Full-length & la & $2 \mathrm{n} 0 \mathrm{a}$ \\
\hline $\begin{array}{l}\text { (Rodriguez } \\
\text { et al., 2015) }\end{array}$ & $\begin{array}{l}5 \mathrm{mM} \text { lithium } \\
\text { hydroxide } \\
20 \mathrm{mM} \text { sodium } \\
\text { phosphate } \\
0.1 \mathrm{M} \mathrm{NaCl}\end{array}$ & 7.5 & $37^{\circ} \mathrm{C}$ & $72 \mathrm{~h}$ & $500 \mu \mathrm{M}$ & Micro-ED & $\begin{array}{l}\text { Peptides: } \\
\text { SubNACore, } \\
\text { NACore, } \\
\text { PreNAC }\end{array}$ & & $\begin{array}{c}4 \text { rik } \\
4 \text { ril } \\
4 \mathrm{znn}\end{array}$ \\
\hline $\begin{array}{l}\text { (Rodriguez } \\
\text { et al., 2015) }\end{array}$ & $\begin{array}{c}50 \mathrm{mM} \text { Tris } \\
150 \mathrm{mM} \mathrm{KCl}\end{array}$ & 7.5 & $37^{\circ} \mathrm{C}$ & $72 \mathrm{~h}$ & $500 \mu \mathrm{M}$ & No structure & Full-length & & \\
\hline $\begin{array}{c}\text { (Gath et al., } \\
2014 b)\end{array}$ & $\begin{array}{c}50 \mathrm{mM} \text { Tris- } \mathrm{HCl} \\
150 \mathrm{mM} \mathrm{KCl}\end{array}$ & 7.5 & $37^{\circ} \mathrm{C}$ & $\begin{array}{l}4 \text { days } \\
(600 \\
\text { r.p.m. }) \\
\end{array}$ & $300 \mu \mathrm{M}$ & $\begin{array}{c}\text { NMR } \\
\text { secondary } \\
\text { structure } \\
\end{array}$ & Full-length & 2 & \\
\hline $\begin{array}{c}\text { (Gath et al., } \\
\text { 2012) }\end{array}$ & $5 \mathrm{mM}$ Tris- $\mathrm{HCl}$ & 7.5 & $37^{\circ} \mathrm{C}$ & $\begin{array}{l}7 \text { days } \\
(600 \\
\text { r.p.m. }) \\
\end{array}$ & $300 \mu \mathrm{M}$ & $\begin{array}{c}\text { NMR } \\
\text { secondary } \\
\text { structure } \\
\end{array}$ & Full-length & \begin{tabular}{|c|} 
Different \\
from 1, \\
2 \\
\end{tabular} & \\
\hline $\begin{array}{l}\text { (Verasdonck } \\
\text { et al., 2016) }\end{array}$ & $5 \mathrm{mM} \mathrm{NaPO} 4$ & 9 & $37^{\circ} \mathrm{C}$ & $\begin{array}{l}4 \text { days } \\
(600 \\
\text { r.p.m. }) \\
\end{array}$ & $300 \mu \mathrm{M}$ & $\begin{array}{c}\text { NMR } \\
\text { secondary } \\
\text { structure }\end{array}$ & Full-length & 1 & \\
\hline This study & $\begin{array}{c}\text { DPBS (Gibco): } \\
2.66 \mathrm{mM} \mathrm{KCl}, \\
1.47 \mathrm{mM} \mathrm{KH} 2 \mathrm{PO} 4, \\
137.93 \mathrm{mM} \mathrm{NaCl}, \\
8.06 \mathrm{mM} \mathrm{Na} 2 \mathrm{HPO} 4 \\
\end{array}$ & 7 to 7.3 & $37^{\circ} \mathrm{C}$ & $\begin{array}{l}5 \text { days } \\
(1000 \\
\text { r.p.m. })\end{array}$ & $\begin{array}{c}360 \mu \mathrm{M} \\
(5 \\
\mathrm{mg} / \mathrm{mL})\end{array}$ & Cryo-EM & $\begin{array}{l}\text { Full-length, } \\
\text { E46K }\end{array}$ & $2 \mathrm{a}$ & \\
\hline This study & $\begin{array}{c}\text { DPBS (Gibco): } \\
2.66 \mathrm{mM} \mathrm{KCl}, \\
1.47 \mathrm{mM} \mathrm{KH} 2 \mathrm{PO} 4, \\
137.93 \mathrm{mM} \mathrm{NaCl}, \\
8.06 \mathrm{mM} \mathrm{Na} 2 \mathrm{HPO} 4 \\
\end{array}$ & 7 to 7.3 & $37^{\circ} \mathrm{C}$ & $\begin{array}{l}5 \text { days } \\
(1000 \\
\text { r.p.m. })\end{array}$ & $\begin{array}{c}360 \mu \mathrm{M} \\
(5 \\
\mathrm{mg} / \mathrm{mL})\end{array}$ & Cryo-EM & $\begin{array}{l}\text { Full-length, } \\
\text { N-terminal } \\
\text { acetylated }\end{array}$ & $2 \mathrm{a}$ & \\
\hline This study & $\begin{array}{c}\text { DPBS (Gibco): } \\
2.66 \mathrm{mM} \mathrm{KCl}, \\
1.47 \mathrm{mM} \mathrm{KH} 2 \mathrm{PO} 4 \\
137.93 \mathrm{mM} \mathrm{NaCl}, \\
8.06 \mathrm{mM} \mathrm{Na} 2 \mathrm{HPO} 4\end{array}$ & 7 to 7.3 & $37^{\circ} \mathrm{C}$ & $\begin{array}{l}5 \text { days } \\
(1000 \\
\text { r.p.m. })\end{array}$ & $\begin{array}{c}360 \mu \mathrm{M} \\
(5 \\
\mathrm{mg} / \mathrm{mL})\end{array}$ & Cryo-EM & \begin{tabular}{|c|} 
Full-length, \\
Phosphorylation \\
at position S129
\end{tabular} & $2 \mathrm{a}$ & \\
\hline
\end{tabular}


bioRxiv preprint doi: https://doi.org/10.1101/654582; this version posted November 21, 2019. The copyright holder for this preprint (which was not certified by peer review) is the author/funder, who has granted bioRxiv a license to display the preprint in perpetuity. It is made available under aCC-BY-NC-ND 4.0 International license.

\begin{tabular}{|c|c|c|c|c|c|}
\hline & $\begin{array}{l}\text { E46K } \\
\text { mutant }\end{array}$ & $\begin{array}{l}\text { Phosphory } \\
\text { lated }\end{array}$ & $\begin{array}{l}\mathrm{N} \text {-terminal } \\
\text { acetylated }\end{array}$ & $\begin{array}{c}\alpha-S y n \\
\text { polymorp } \\
\text { h 2a }\end{array}$ & $\begin{array}{c}\alpha-S y n \\
\text { polymorp } \\
\text { h 2b }\end{array}$ \\
\hline \multicolumn{6}{|l|}{ Data Collection } \\
\hline Pixel size $[\AA]$ & 0.831 & 0.831 & 0.831 & 0.629 & 0.629 \\
\hline Defocus Range $[\mu \mathrm{m}]$ & -0.8 to -2.5 & -0.8 to -2.5 & -0.8 to -2.5 & -0.8 to -2.5 & -0.8 to -2.5 \\
\hline Voltage $[\mathrm{kV}]$ & 300 & 300 & 300 & 300 & 300 \\
\hline Exposure time [s per frame] & 0.2 & 0.2 & 0.2 & 0.2 & 0.2 \\
\hline Number of frames & 50 & 50 & 50 & 50 & 50 \\
\hline Total dose $\left[\mathrm{e}^{-} / \AA^{2}\right]$ & 69 & 69 & 69 & 69 & 69 \\
\hline \multicolumn{6}{|l|}{ Reconstruction } \\
\hline Box width [pixels] & 280 & 280 & 280 & 280 & 280 \\
\hline Inter-box distance [pixels] & 28 & 28 & 28 & 28 & 28 \\
\hline Micrographs & 843 & 1'887 & 948 & $1 ' 143$ & $1 ’ 143$ \\
\hline Manually picked fibrils & 2’702 & $5 ’ 095$ & 3’751 & $5 ’ 233$ & $5 ’ 233$ \\
\hline Initially extracted segments & $65^{\prime} 893$ & $107^{\prime} 144$ & $43^{\prime} 276$ & $100 ’ 323$ & $100^{\prime} 323$ \\
\hline Segments after 2D classification & $50 ’ 514$ & $107^{\prime} 126$ & 35342 & $100 ’ 193$ & $100 ’ 193$ \\
\hline Segments after 3D classification & $50 ’ 514$ & $21^{\prime} 685$ & 35342 & $19^{\prime} 937$ & 3'989 \\
\hline Resolution after 3D refinement $[\AA]$ & 4.65 & 4.65 & 4.75 & 3.34 & 3.75 \\
\hline Final resolution $[\AA]$ & 4.56 & 4.31 & 4.39 & 2.99 & 3.39 \\
\hline Estimated map sharpening B-factor $\left[\AA^{2}\right]$ & -208.6 & -104.3 & -178.1 & -67.1 & -76.4 \\
\hline Helical rise $[\AA]$ & 4.85 & 4.84 & 4.78 & 4.80 & 2.40 \\
\hline Helical twist $\left[{ }^{\circ}\right]$ & -0.79 & -0.77 & -0.71 & -0.80 & 179.55 \\
\hline
\end{tabular}

Table 2: Cryo-EM structure determination statistics 
bioRxiv preprint doi: https://doi.org/10.1101/654582; this version posted November 21,2019 . The copyright holder for this preprint (which was not certified by peer review) is the author/funder, who has granted bioRxiv a license to display the preprint in perpetuity. It is made available under aCC-BY-NC-ND 4.0 International license.

Guerrero-Ferreira et al., Polymorphism in alpha-synuclein fibrils 20

\begin{tabular}{|c|c|c|}
\hline & a-Syn polymorph $2 a$ & a-Syn polymorph $2 b$ \\
\hline Initial model used [PDB code] & $6 s s x$ & 6 sst \\
\hline $\begin{array}{r}\text { Model resolution }[\AA] \\
(\mathrm{FSC}=0.143) \\
\end{array}$ & 2.98 & 3.4 \\
\hline Model resolution range $[\AA]]$ & 2.98 & 3.1 \\
\hline Map sharpening $B$-factor $\left[\AA^{2}\right]$ & -67.1 & -76.4 \\
\hline $\begin{array}{l}\text { Model composition } \\
\text { Non-hydrogen atoms } \\
\text { Protein residues } \\
\text { Ligands }\end{array}$ & $\begin{array}{c}4900 \\
730 \\
0\end{array}$ & $\begin{array}{c}4900 \\
730 \\
0\end{array}$ \\
\hline $\begin{array}{l}B \text {-factors }\left[\AA^{2}\right] \text { (non-hydrogen atoms) } \\
\text { Protein } \\
\text { Ligand }\end{array}$ & $\begin{array}{c}48.18 \\
-\end{array}$ & $\begin{array}{c}70.32 \\
-\end{array}$ \\
\hline $\begin{array}{l}\text { R.m.s. deviations } \\
\text { Bond lengths }[\AA] \\
\text { Bond angles }\left[{ }^{\circ}\right] \\
\end{array}$ & $\begin{array}{l}0.008 \\
0.938 \\
\end{array}$ & $\begin{array}{l}0.009 \\
0.941 \\
\end{array}$ \\
\hline $\begin{array}{l}\text { Validation } \\
\text { MolProbity score } \\
\text { Clashscore } \\
\text { Poor rotamers [\%] }\end{array}$ & $\begin{array}{l}2.43 \\
6.14 \\
4.26 \\
\end{array}$ & $\begin{array}{l}2.11 \\
5.73 \\
2.13 \\
\end{array}$ \\
\hline $\begin{array}{l}\text { Ramachandran plot } \\
\text { Favored [\%] } \\
\text { Allowed [\%] } \\
\text { Disallowed [\%] }\end{array}$ & $\begin{array}{c}87.39 \\
12.61 \\
0.00 \\
\end{array}$ & $\begin{array}{c}89.86 \\
10.14 \\
0.00 \\
\end{array}$ \\
\hline
\end{tabular}

Table 3: Model building statistics 
bioRxiv preprint doi: https://doi.org/10.1101/654582; this version posted November 21, 2019. The copyright holder for this preprint (which was not certified by peer review) is the author/funder, who has granted bioRxiv a license to display the preprint in perpetuity. It is made available under aCC-BY-NC-ND 4.0 International license.

Guerrero-Ferreira et al., Polymorphism in alpha-synuclein fibrils

\section{Figures}

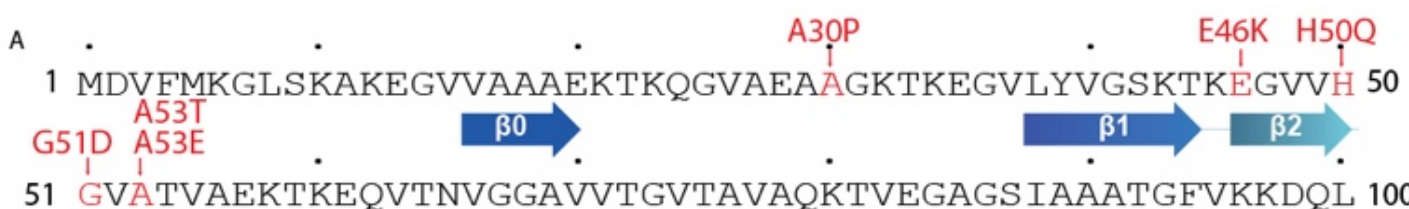

51 GVATVAEKTKEQVTNVGGAVVTGVTAVAQKTVEGAGSIAAATGFVKKDQL 100

101 GKNEEGAPQEGILEDMPVDPDNEAYEMPSEEGYQDYEPEA

B

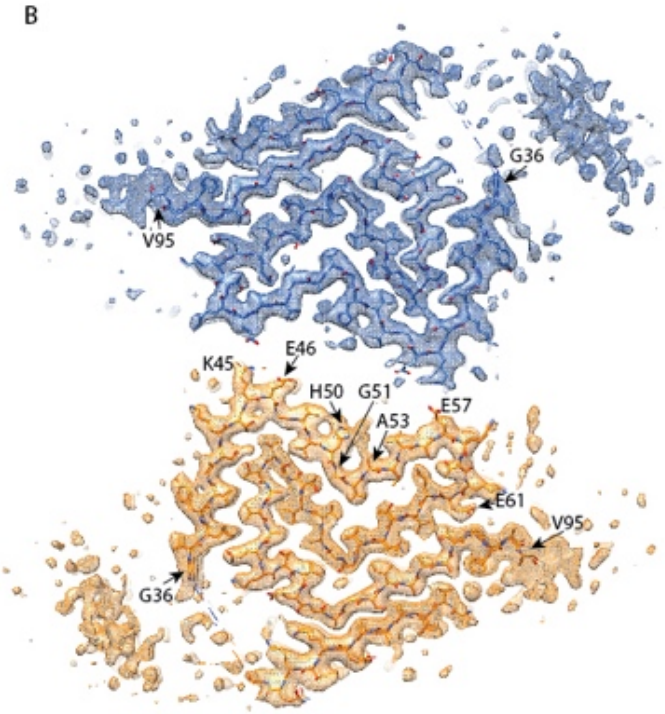

Polymorph 2a

D
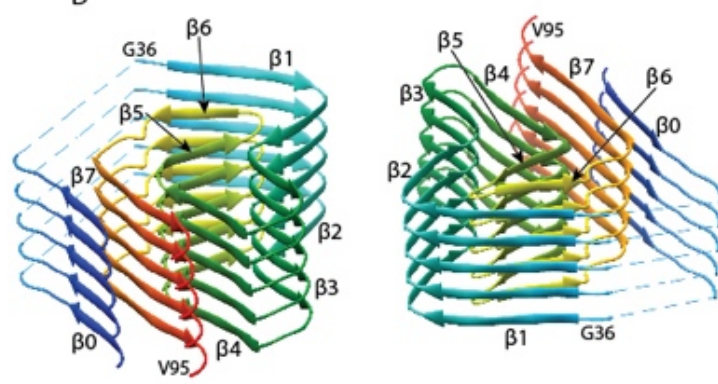

C

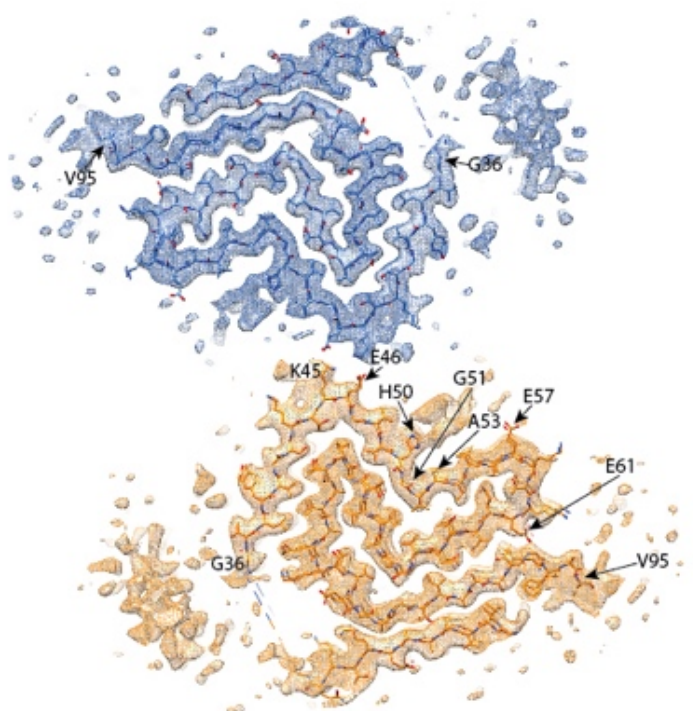

Polymorph $2 b$

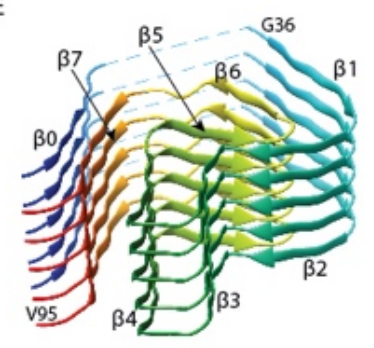

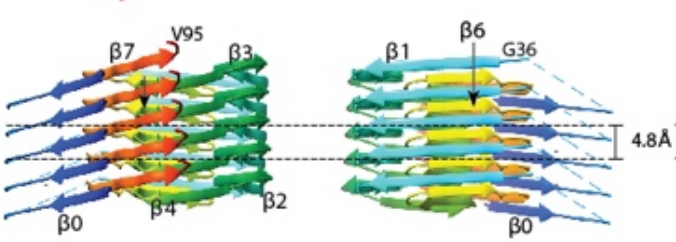
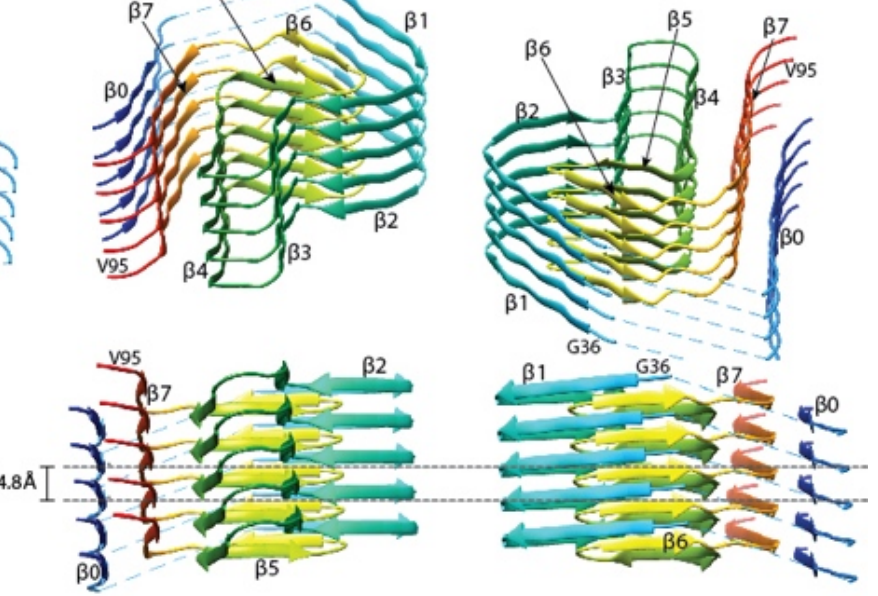

Figure 1. Cross-sections of the $\alpha-S y n$ polymorph 2 a and 2 b cryo-EM structures.

(A) Sequence of human $\alpha$-Syn with familial PD mutation sites indicated in red. $\beta$ strands are indicated by arrows colored from blue to orange. Cryo-EM densities and atomic models of polymorph $2 \mathrm{a}$ (B) and polymorph $2 \mathrm{~b}$ (C) of $\alpha$-Syn. Each cryo-EM map shows two protofilaments (blue and orange) forming a fibril. PD-associated mutations sites, and first and last residues of the NAC regions are indicated. (D) and (E) Rainbow rendering views of the secondary structure elements in five successive rungs of both polymorphs. A view 
perpendicular to the helical axis is shown to illustrate the height differences in a single $\alpha$-Syn fibril. Colors correspond to the arrows in the sequence displayed in panel (A).
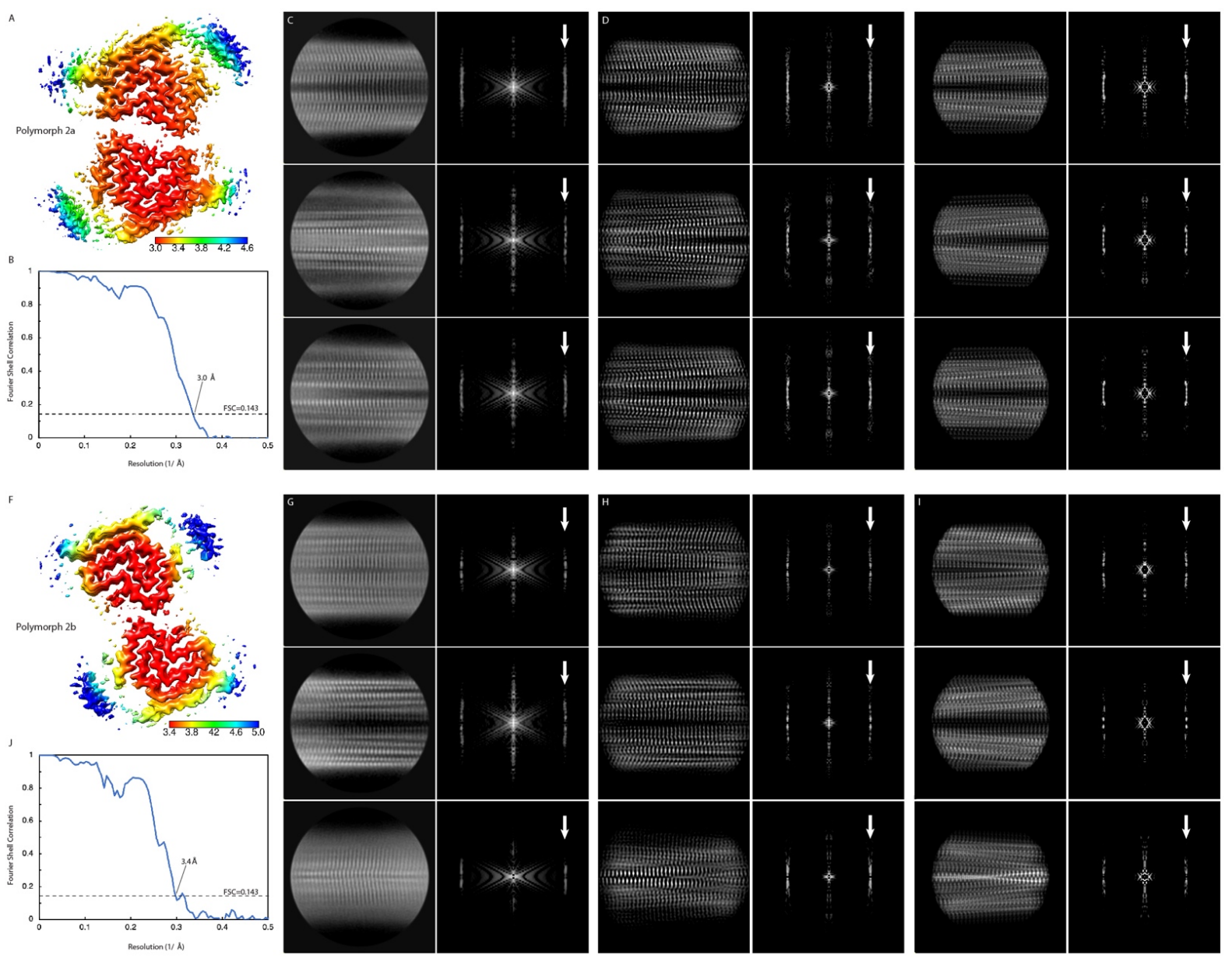

Figure 1-figure supplement 1. Local resolution estimation and FSC curves.

Cryo EM maps with local resolution estimations for $\alpha$-Syn polymorph 2a (A) and $\alpha$-Syn polymorph $2 \mathrm{~b}(\mathrm{~F})$. The color scales indicate the resolution values within each map. (B) and (J) Fourier shell correlation curves between two independently refined half-maps. Overall resolutions are indicated. $(\mathrm{C})$ and $(\mathrm{G})$ Reference-free $2 \mathrm{D}$ class averages with their power spectra. (D) and (H) 2D projections of the cryo-EM maps with their power spectra. (E) and (I) $2 \mathrm{D}$ projection of the atomic models with their power spectra. White arrows in spectrum panels indicate the layer line at $1 / 4.8 \AA$ with either a meridional $n=0$ Bessel function peak $(\alpha$ Syn polymorph 2a, panels (C) (D) and (E)), or off-meridional $n=1$ Bessel function peak intensities ( $\alpha$-Syn polymorph $2 b$, panels $(G)(H)$ and $(I))$. 

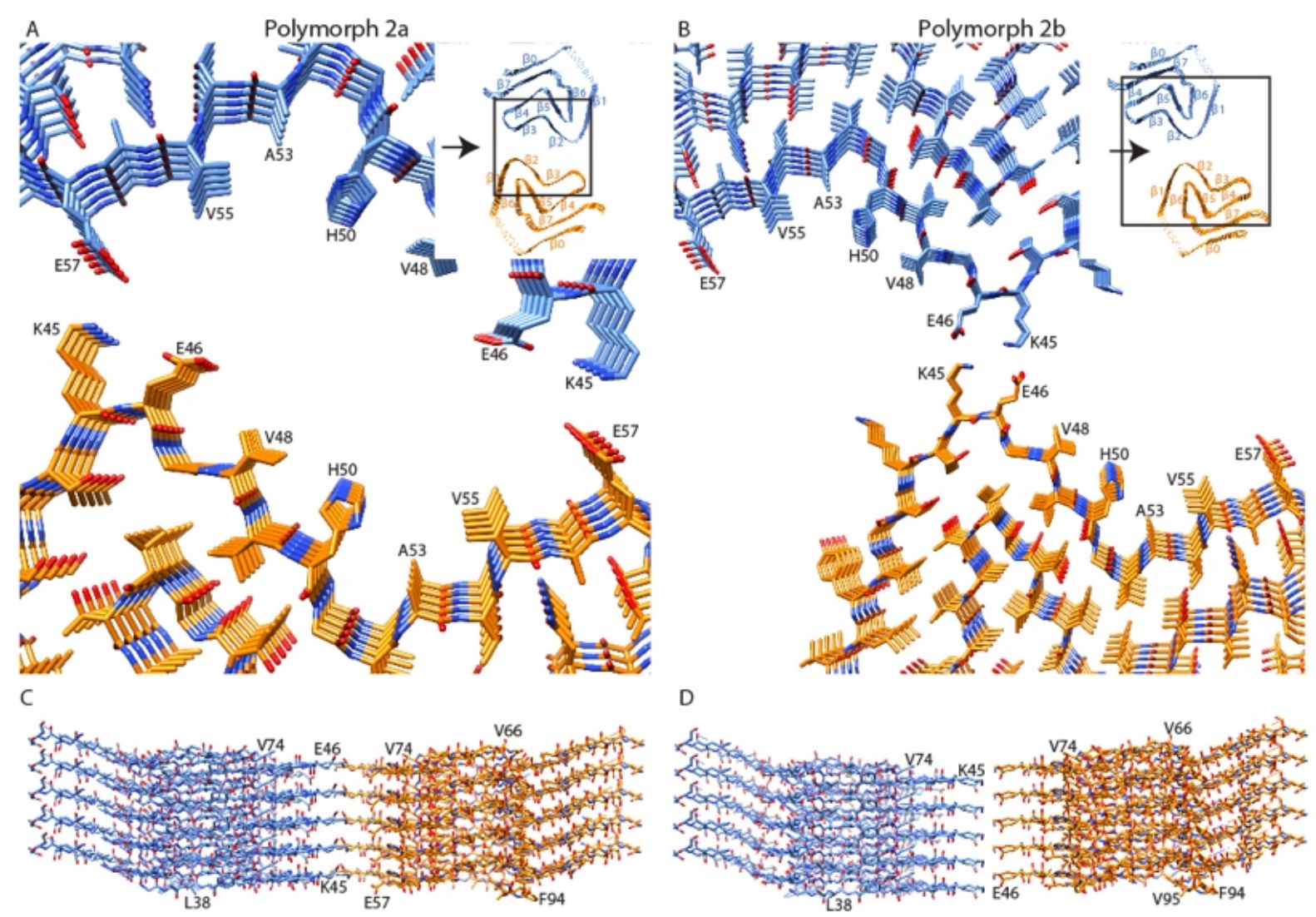

Figure 1-figure supplement 2. Interface regions between two protofilaments of the $\alpha$ Syn polymorph $2 \mathrm{a}$ and $2 \mathrm{~b}$.

(A) and (B) Views along the axis of the $\alpha$-Syn polymorph $2 \mathrm{a}$ and $2 \mathrm{~b}$ fibrils, respectively. The area shown is highlighted with squares in the ribbon diagrams (inserts). (C) and (D) Side views of the fibrils showing the side-by-side alignment of $\alpha$-Syn molecules in polymorph $2 \mathrm{a}$ (C), compared to the staggered packing of $\alpha$-Syn molecules in polymorph $2 b(D)$. Viewing directions in (C) and (D) are indicated by arrows in the ribbon diagrams. 

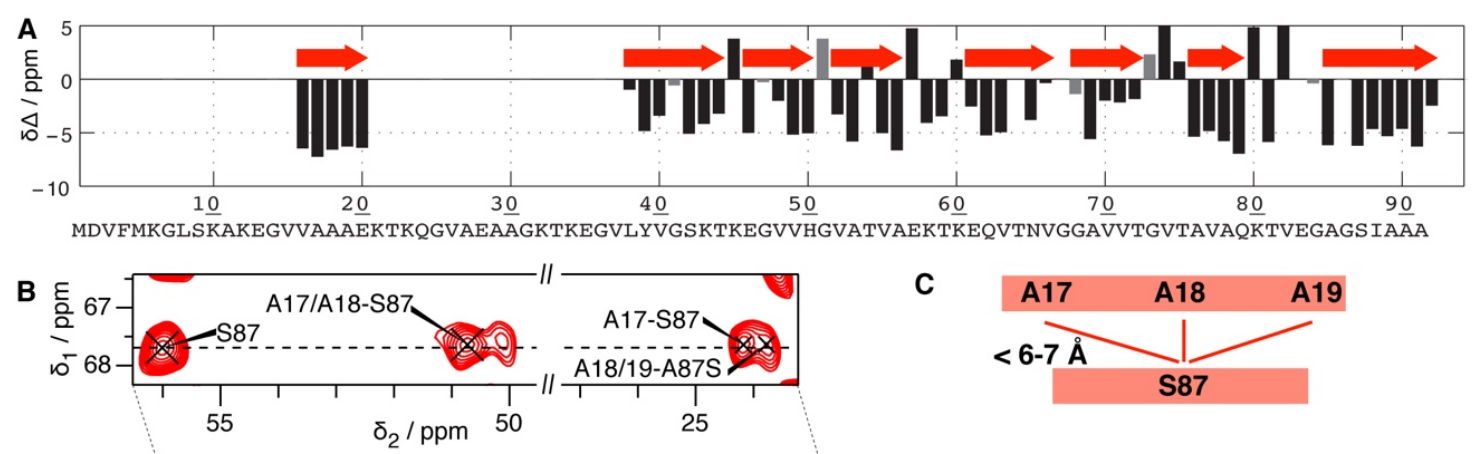

C

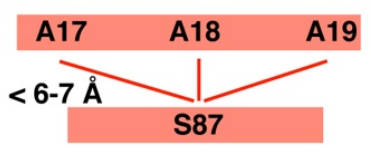

D

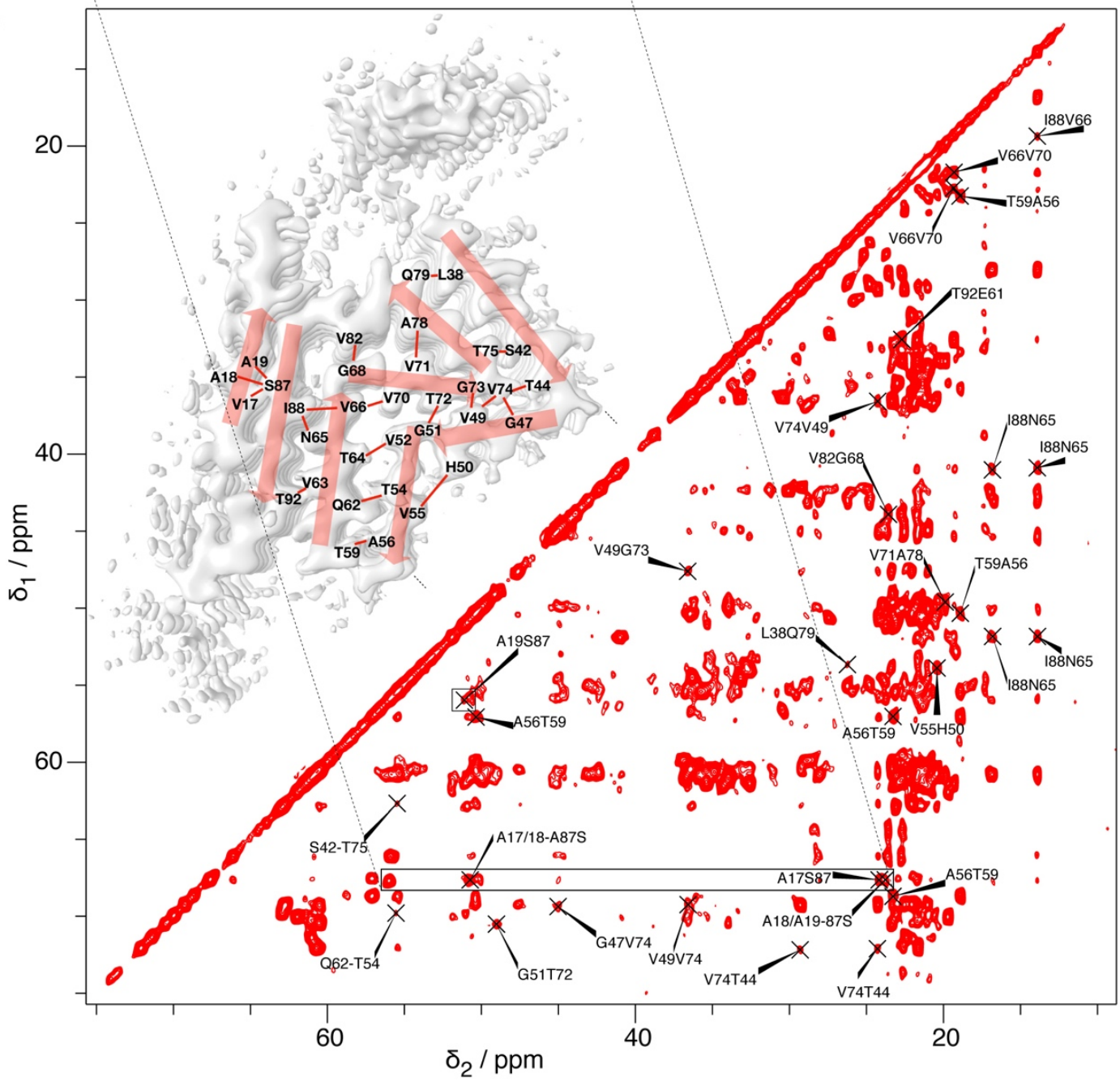

Figure 1-figure supplement 3. NMR identification of the residues forming the Nterminal beta strand. (A) NMR secondary chemical shift plot according to reference (Gath et al., 2014b). $\beta$-strands are revealed when three or more residues in a row show a negative difference of the secondary shifts $\Delta \delta$ (the difference between the chemical-shift deviations of the observed $\mathrm{C} \alpha$ and $\mathrm{C} \beta$ shifts from the random coil shift). This information is plotted on the cryo-EM structure in red. (B) Extract of a $2 \mathrm{D}{ }^{13} \mathrm{C}-{ }^{13} \mathrm{C}$ PAR spectrum (full aliphatic region shown in (D) of the cross peaks assigned to S87-A17, A18, A19 interactions, for which all assignment possibilities within $0.15 \mathrm{ppm}$ are indicated. (C) Structural restraints resulting from the cross signals in (B), and from the A19S87 peak highlighted by a box in (D), where the full $2 \mathrm{D}{ }^{13} \mathrm{C}-{ }^{13} \mathrm{C}$ PAR NMR spectrum is shown with assigned peaks corresponding to at least $\mathrm{i}, \mathrm{i} \pm 3$ contacts (non-trivial structural restraints). Most of these peaks are ambiguous, i.e., 
have several assignment possibilities within $0.15 \mathrm{ppm}$, which were lifted here by comparison with the cryo-EM structures. This illustrates that the PAR spectrum indeed contains numerous structurally meaningful inter- $\beta$-strand restraints that confirm the interpretation of the electron densities, even if the assignment ambiguities did not allow for an NMR 3D structure determination.
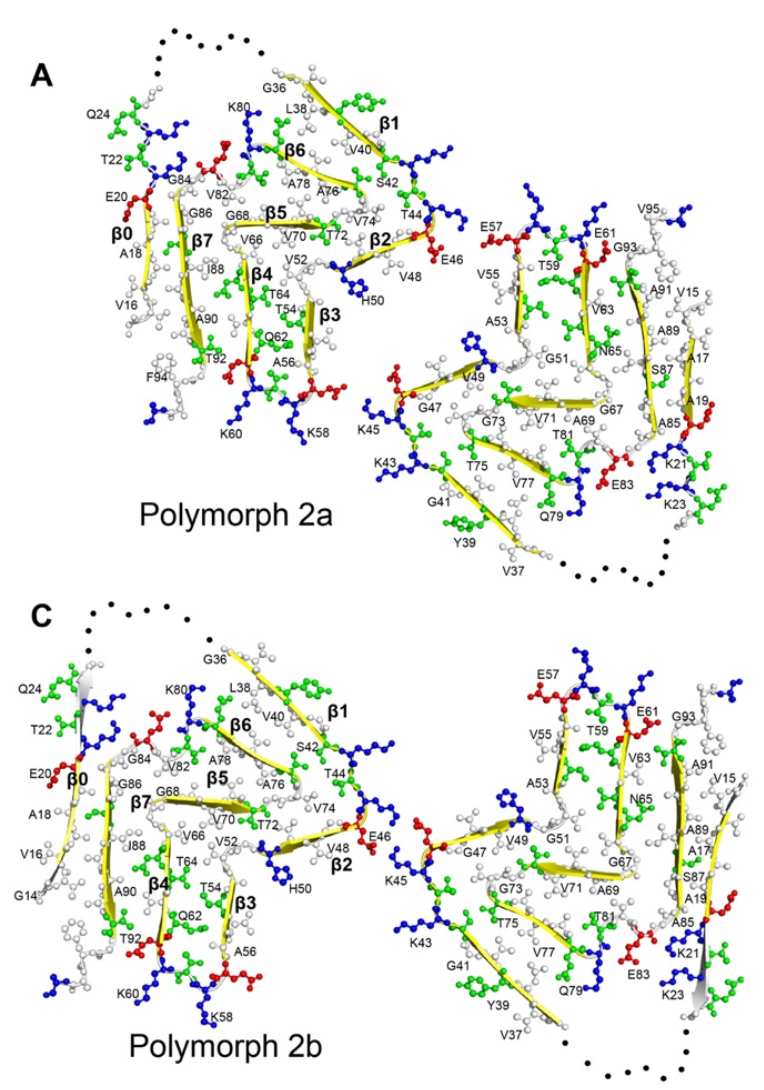

B
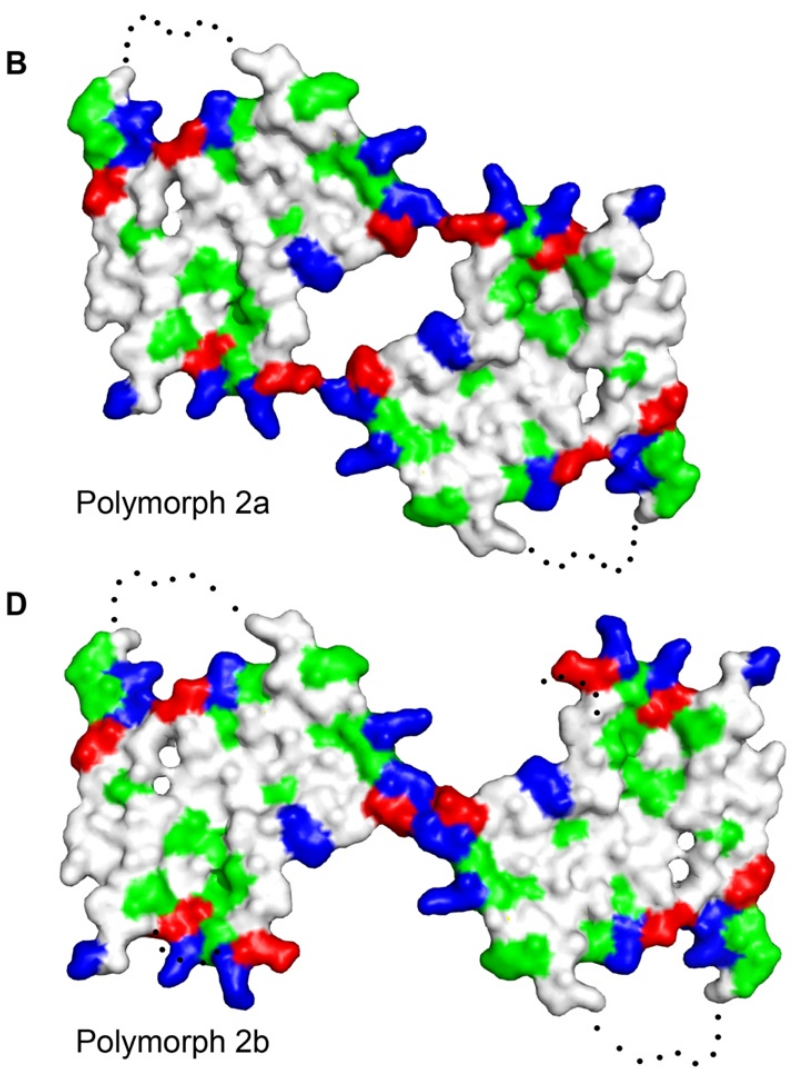

Figure 2. Structure and distribution of amino acids in the new $\alpha$-Syn fibril polymorphs. Amino acids are colored in blue for positively charged, in red for negatively charged, in green for polar (including glycine), and in white for hydrophobic residues. Even and odd numberings are given on one monomer each. (A) and (C) Backbone structure. (B) and (D) Surface view. 

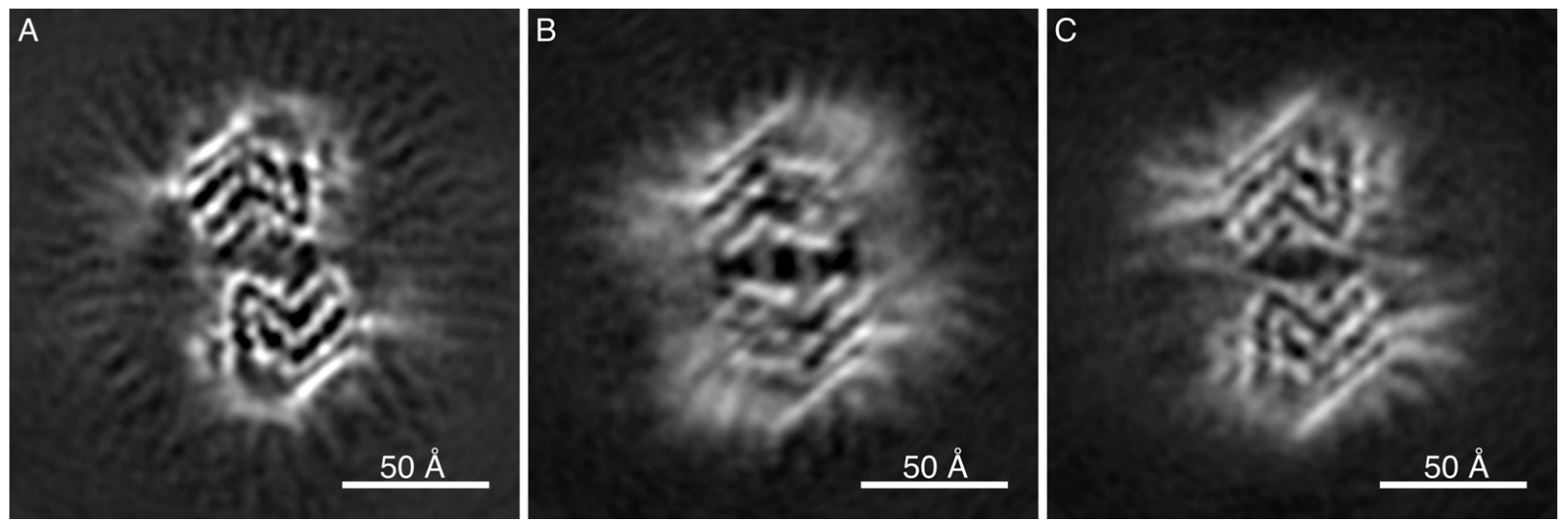

Figure 3. Cryo-EM cross-sections of fibrils, formed by E46K, p-S129 phosphorylated, and $\mathrm{N}$-terminally acetylated $\alpha$-Syn protein.

Fibrils formed by E46K mutant $\alpha$-Syn protein (A), Ser129 phosphorylated $\alpha$-Syn protein (B), and $\mathrm{N}$-terminally acetylated $\alpha$-Syn protein $(C)$ were analyzed by cryo-EM. Image processing did not allow reaching sufficient resolution for model building, but the cross-sections of the obtained 3D reconstructions are compatible with polymorph 2a for all three forms. 
A

1

61

95

140

\section{$\mathrm{N}$-terminus}

NAC

B

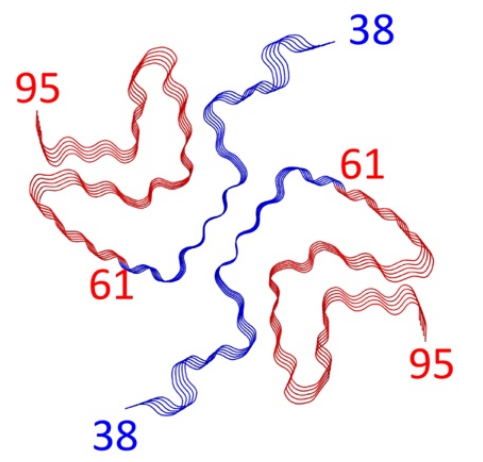

43

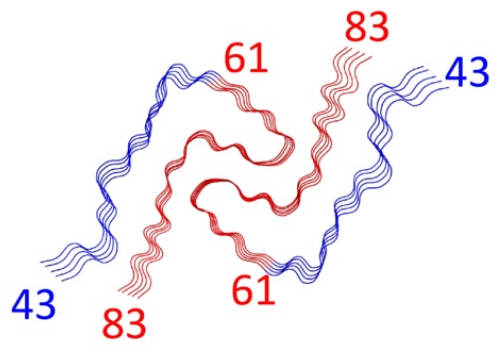

\section{Polymorph 1a (6h6b)}

\section{Polymorph $1 \mathrm{~b}$ (6cu8)}

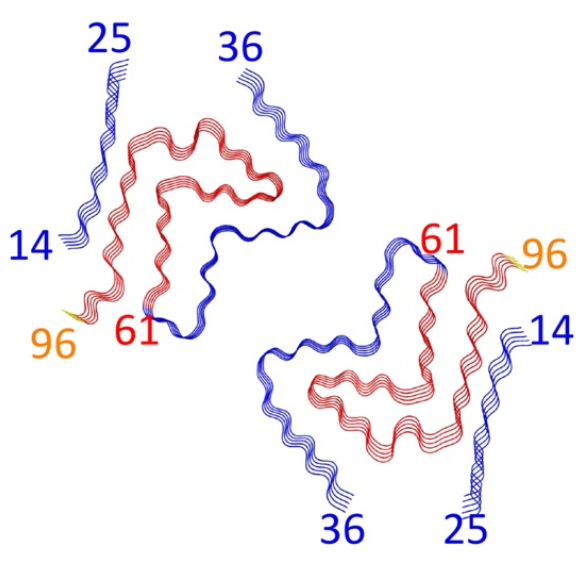

Polymorph 2a (6rt0)

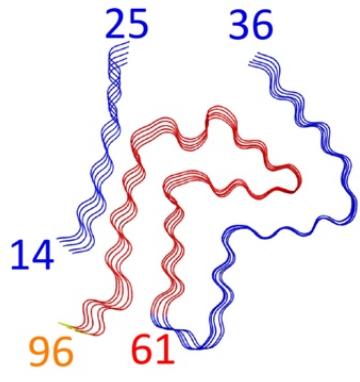

Polymorph $2 b$ (6rtb)

Figure 4. Schematic representation of $\alpha$-Syn polymorphs.

(A) Diagram representing $\alpha$-Syn regions with the N-terminus in blue, the NAC region in red and the C-terminus in yellow. (B) Representation of $\alpha$-Syn fibril polymorphs 1a (PDB ID 6h6b, (Guerrero-Ferreira et al., 2018)), 1b (PDB ID 6cu8, (Li et al., 2018a)), 2a (PDB ID 6rt0, this work), and $2 \mathrm{~b}$ (PDB ID 6rtb, this work), highlighting the striking differences in protofilament folding in $\alpha$-Syn polymorphs $1 \mathrm{a}$ and $1 \mathrm{~b}$, compared to $\alpha$-Syn polymorphs $2 \mathrm{a}$ and $2 \mathrm{~b}$. The atomic models obtained by cryo-EM of $\alpha$-Syn polymorph $1 \mathrm{a}$, polymorph $1 \mathrm{~b}$ ( $\mathrm{Li}$ et al., 2018a; Li et al., 2018b) and $\alpha$-Syn polymorphs 2a and 2b (this work). Protein Data Bank (PDB) accession numbers are indicated. 


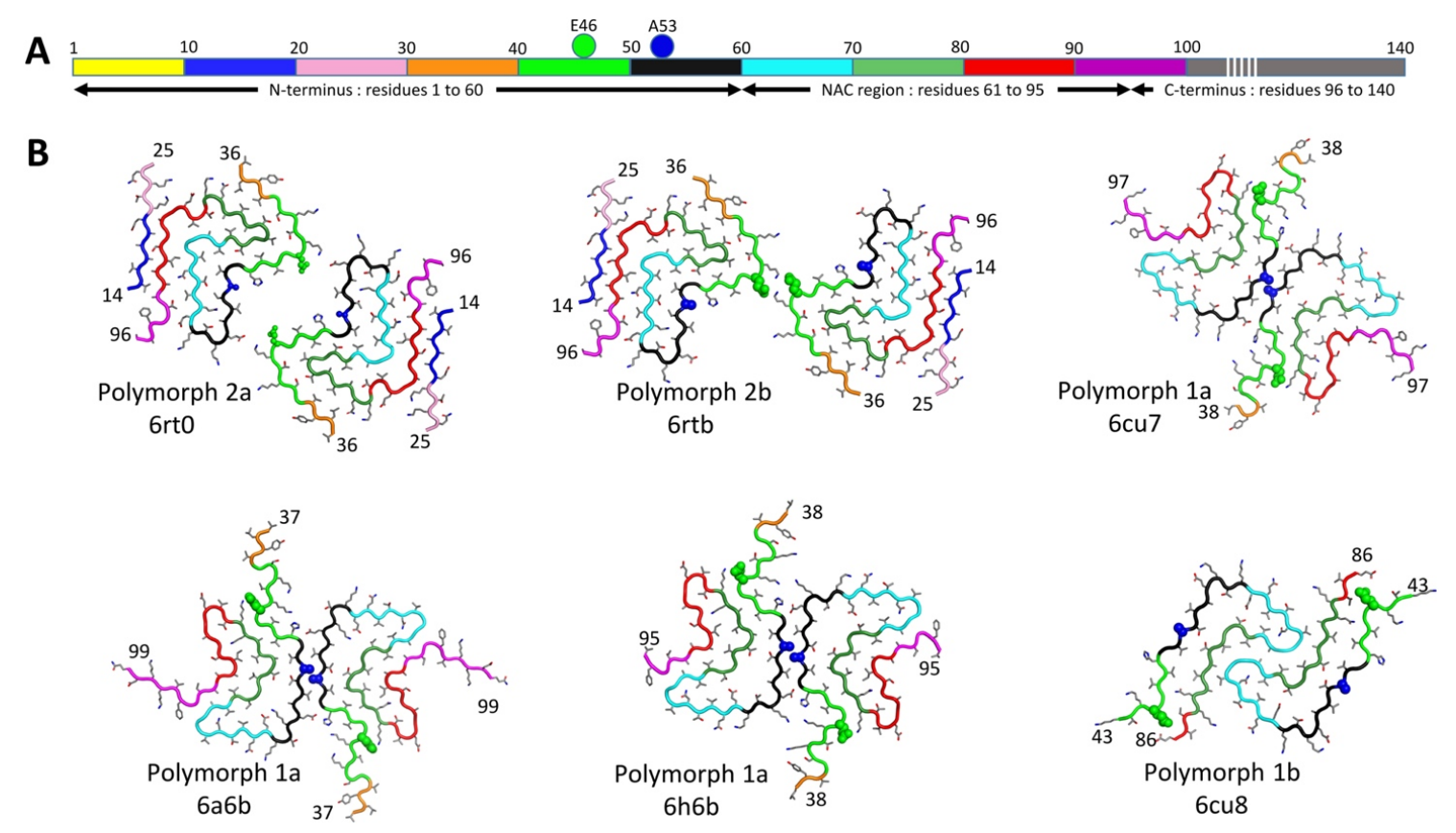

Figure 4-figure supplement 1. Comparison between polymorphs 1 and 2.

Structures of polymorphs $1 \mathrm{a}, \mathrm{b}$ and $2 \mathrm{a}, \mathrm{b}$ with backbone shown in alternating colors in order to distinguish the location of the segments in the different structures. (A) Diagram representing $\alpha$-Syn color coding from $\mathrm{N}$-terminus to $\mathrm{C}$-terminus: 1-10, yellow; 11-20, blue; 21-30, pink; 31-40, orange; 41-50 green; 51-60, black; 61-70, cyan; 71-80, light green; 81-90, red; 91-100 magenta; 101-140, grey. (B) Worm representation of $\alpha$-Syn fibril polymorphs 1a, 1b, $2 \mathrm{a}$ and $2 \mathrm{~b}$. N-terminal and C-terminal residues number are indicated. Residues E53 and A53 are shown by van-der-Waals representation of the residues in green and blue respectively. Other residues are given in stick representation. Polymorph type, and PDB accession codes are indicated.

\section{Video Captions}

\section{Video 1. Comparison of cryo-EM maps of $\alpha$-Syn fibril polymorphs.}

Cryo-EM reconstructions of $\alpha$-Syn fibrils at $3.1 \AA$ (polymorph $2 \mathrm{a}$ ) and $3.5 \AA$ (polymorph $2 \mathrm{~b}$ ) resolution detailing the interaction between two protofilaments (blue and orange) in each fibril, the $4.9 \AA$ spacing between $\beta$-strands and the topology of $\alpha$-Syn monomers within a single protofilament.

\section{Video 2. Structural differences between $\alpha-S y n$ polymorphs.}

Atomic models of $\alpha$-Syn fibrils represented as rounded ribbons with the $\mathrm{N}$-terminus in blue and the NAC region in red. 


\section{REFERENCES}

Afonine, P.V., Headd, J.J., Terwilliger, T.C., Adams, P.D., 2013. New tool: phenix real_space refine. Comp. Crystal. Newsletter 4(2), 43-44.

Appel-Cresswell, S., Vilarino-Guell, C., Encarnacion, M., Sherman, H., Yu, I., Shah, B., Weir, D., Thompson, C., Szu-Tu, C., Trinh, J., Aasly, J.O., Rajput, A., Rajput, A.H., Jon Stoessl, A., Farrer, M.J., 2013. Alpha-synuclein p.H50Q, a novel pathogenic mutation for Parkinson's disease. Mov Disord 28(6), 811-813.

Bassil, F., Fernagut, P.-O., Bezard, E., Pruvost, A., Leste-Lasserre, T., Hoang, Q.Q., Ringe, D., Petsko, G.A., Meissner, W.G., 2016. Reducing C-terminal truncation mitigates synucleinopathy and neurodegeneration in a transgenic model of multiple system atrophy. Proceedings of the National Academy of Sciences 113(34), 9593-9598.

Biyani, N., Righetto, R.D., McLeod, R., Caujolle-Bert, D., Castano-Diez, D., Goldie, K.N., Stahlberg, H., 2017. Focus: The interface between data collection and data processing in cryo-EM. J Struct Biol 198(2), 124-133.

Bousset, L., Pieri, L., Ruiz-Arlandis, G., Gath, J., Jensen, P.H., Habenstein, B., Madiona, K., Olieric, V., Böckmann, A., Meier, B.H., Melki, R., 2013. Structural and functional characterization of two alpha-synuclein strains. Nat Commun 42575.

Campioni, S., Carret, G., Jordens, S., Nicoud, L., Mezzenga, R., Riek, R., 2014. The presence of an air-water interface affects formation and elongation of alpha-Synuclein fibrils. J Am Chem Soc 136(7), 2866-2875.

Chartier-Harlin, M.C., Kachergus, J., Roumier, C., Mouroux, V., Douay, X., Lincoln, S., Levecque, C., Larvor, L., Andrieux, J., Hulihan, M., Waucquier, N., Defebvre, L., Amouyel, P., Farrer, M., Destee, A., 2004. Alpha-synuclein locus duplication as a cause of familial Parkinson's disease. Lancet 364(9440), 1167-1169.

Close, W., Neumann, M., Schmidt, A., Hora, M., Annamalai, K., Schmidt, M., Reif, B., Schmidt, V., Grigorieff, N., Fandrich, M., 2018. Physical basis of amyloid fibril polymorphism. Nat Commun 9(1), 699.

Comellas, G., Lemkau, L.R., Zhou, D.H., George, J.M., Rienstra, C.M., 2012. Structural intermediates during alpha-synuclein fibrillogenesis on phospholipid vesicles. J Am Chem Soc 134(11), 5090-5099.

Comellas, G., Lemkau, L.R., Nieuwkoop, A.J., Kloepper, K.D., Ladror, D.T., Ebisu, R., Woods, W.S., Lipton, A.S., George, J.M., Rienstra, C.M., 2011. Structured regions of alpha-synuclein fibrils include the early-onset Parkinson's disease mutation sites. J Mol Biol 411(4), 881-895.

Conway, K.A., Harper, J.D., Lansbury, P.T., 1998. Accelerated in vitro fibril formation by a mutant alpha-synuclein linked to early-onset Parkinson disease. Nature medicine 4(11), 1318-1320.

Crowther, R.A., Daniel, S.E., Goedert, M., 2000. Characterisation of isolated alpha-synuclein filaments from substantia nigra of Parkinson's disease brain. Neuroscience letters 292(2), 128-130.

Crowther, R.A., Jakes, R., Spillantini, M.G., Goedert, M., 1998. Synthetic filaments assembled from C-terminally truncated alpha-synuclein. FEBS Lett 436(3), 309-312.

De Paepe, G., Lewandowski, J.R., Loquet, A., Böckmann, A., Griffin, R.G., 2008. Proton assisted recoupling and protein structure determination. J Chem Phys 129(24), 245101.

Dettmer, U., Ramalingam, N., von Saucken, V.E., Kim, T.E., Newman, A.J., Terry-Kantor, E., Nuber, S., Ericsson, M., Fanning, S., Bartels, T., Lindquist, S., Levy, O.A., 
Selkoe, D., 2017. Loss of native alpha-synuclein multimerization by strategically mutating its amphipathic helix causes abnormal vesicle interactions in neuronal cells. Hum Mol Genet 26(18), 3466-3481.

Dufty, B.M., Warner, L.R., Hou, S.T., Jiang, S.X., Gomez-Isla, T., Leenhouts, K.M., Oxford, J.T., Feany, M.B., Masliah, E., Rohn, T.T., 2007. Calpain-cleavage of alphasynuclein: connecting proteolytic processing to disease-linked aggregation. Am J Pathol 170(5), 1725-1738.

El-Agnaf, O.M., Jakes, R., Curran, M.D., Middleton, D., Ingenito, R., Bianchi, E., Pessi, A., Neill, D., Wallace, A., 1998. Aggregates from mutant and wild-type alpha-synuclein proteins and NAC peptide induce apoptotic cell death in human neuroblastoma cells by formation of beta-sheet and amyloid-like filaments. FEBS Lett 440(1-2), 71-75.

Emsley, P., Cowtan, K., 2004. Coot: model-building tools for molecular graphics. Acta Crystallogr D Biol Crystallogr 60(Pt 12 Pt 1), 2126-2132.

Falcon, B., Zhang, W., Murzin, A.G., Murshudov, G., Garringer, H.J., Vidal, R., Crowther, R.A., Ghetti, B., Scheres, S.H.W., Goedert, M., 2018. Structures of filaments from Pick's disease reveal a novel tau protein fold. Nature 561(7721), 137-140.

Falcon, B., Zivanov, J., Zhang, W., Murzin, A.G., Garringer, H.J., Vidal, R., Crowther, R.A., Newell, K.L., Ghetti, B., Goedert, M., Scheres, S.H.W., 2019. Novel tau filament fold in chronic traumatic encephalopathy encloses hydrophobic molecules. Nature 568(7752), 420-423.

Fandrich, M., Nystrom, S., Nilsson, K.P.R., Böckmann, A., LeVine, H., 3rd, Hammarstrom, P., 2018. Amyloid fibril polymorphism: a challenge for molecular imaging and therapy. J Intern Med 283(3), 218-237.

Fitzpatrick, A.W.P., Falcon, B., He, S., Murzin, A.G., Murshudov, G., Garringer, H.J., Crowther, R.A., Ghetti, B., Goedert, M., Scheres, S.H.W., 2017. Cryo-EM structures of tau filaments from Alzheimer's disease. Nature 547(7662), 185-190.

Flagmeier, P., Meis1, G., Vendruscolo, M., Knowles, T.P., Dobson, C.M., Buell, A.K., Galvagnion, C., 2016. Mutations associated with familial Parkinson's disease alter the initiation and amplification steps of alpha-synuclein aggregation. Proc Natl Acad Sci U S A 113(37), 10328-10333.

Fujioka, S., Ogaki, K., Tacik, P.M., Uitti, R.J., Ross, O.A., Wszolek, Z.K., 2014. Update on novel familial forms of Parkinson's disease and multiple system atrophy. Parkinsonism \& related disorders 20 Suppl 1S29-34.

Gath, J., Habenstein, B., Bousset, L., Melki, R., Meier, B.H., Böckmann, A., 2012. Solidstate NMR sequential assignments of alpha-synuclein. Biomol NMR Assign 6(1), 5155.

Gath, J., Bousset, L., Habenstein, B., Melki, R., Böckmann, A., Meier, B.H., 2014a. Unlike twins: an NMR comparison of two alpha-synuclein polymorphs featuring different toxicity. PLoS One 9(3), e90659.

Gath, J., Bousset, L., Habenstein, B., Melki, R., Meier, B.H., Böckmann, A., 2014b. Yet another polymorph of alpha-synuclein: solid-state sequential assignments. Biomol NMR Assign 8(2), 395-404.

George, J.M., 2002. The synucleins. Genome Biol 3(1), REVIEWS3002.

George, J.M., Jin, H., Woods, W.S., Clayton, D.F., 1995. Characterization of a novel protein regulated during the critical period for song learning in the zebra finch. Neuron 15(2), 361-372.

Ghee, M., Melki, R., Michot, N., Mallet, J., 2005. PA700, the regulatory complex of the 26S proteasome, interferes with alpha-synuclein assembly. FEBS J 272(16), 4023-4033. 
Giasson, B.I., Murray, I.V., Trojanowski, J.Q., Lee, V.M., 2001. A hydrophobic stretch of 12 amino acid residues in the middle of alpha-synuclein is essential for filament assembly. J Biol Chem 276(4), 2380-2386.

Gremer, L., Scholzel, D., Schenk, C., Reinartz, E., Labahn, J., Ravelli, R.B.G., Tusche, M., Lopez-Iglesias, C., Hoyer, W., Heise, H., Willbold, D., Schroder, G.F., 2017. Fibril structure of amyloid-beta(1-42) by cryo-electron microscopy. Science 358(6359), 116-119.

Guerrero-Ferreira, R., Taylor, N.M., Mona, D., Ringler, P., Lauer, M.E., Riek, R., Britschgi, M., Stahlberg, H., 2018. Cryo-EM structure of alpha-synuclein fibrils. Elife 7(e36402).

Hashimoto, M., Hsu, L.J., Sisk, A., Xia, Y., Takeda, A., Sundsmo, M., Masliah, E., 1998. Human recombinant NACP/alpha-synuclein is aggregated and fibrillated in vitro: relevance for Lewy body disease. Brain Res 799(2), 301-306.

He, S., Scheres, S.H.W., 2017. Helical reconstruction in RELION. J Struct Biol 198(3), 163176.

Heise, H., Hoyer, W., Becker, S., Andronesi, O.C., Riedel, D., Baldus, M., 2005. Molecularlevel secondary structure, polymorphism, and dynamics of full-length alpha-synuclein fibrils studied by solid-state NMR. Proc Natl Acad Sci U S A 102(44), 15871-15876.

Huang, C., Ren, G., Zhou, H., Wang, C.C., 2005. A new method for purification of recombinant human alpha-synuclein in Escherichia coli. Protein Expr Purif 42(1), 173-177.

Ibanez, P., Bonnet, A.M., Debarges, B., Lohmann, E., Tison, F., Pollak, P., Agid, Y., Durr, A., Brice, A., 2004. Causal relation between alpha-synuclein gene duplication and familial Parkinson's disease. Lancet 364(9440), 1169-1171.

Iwatsubo, T., Yamaguchi, H., Fujimuro, M., Yokosawa, H., Ihara, Y., Trojanowski, J.Q., Lee, V.M., 1996. Purification and characterization of Lewy bodies from the brains of patients with diffuse Lewy body disease. Am J Pathol 148(5), 1517-1529.

Jakes, R., Spillantini, M.G., Goedert, M., 1994. Identification of two distinct synucleins from human brain. FEBS Lett 345(1), 27-32.

Johnson, M., Coulton, A.T., Geeves, M.A., Mulvihill, D.P., 2010. Targeted Amino-Terminal Acetylation of Recombinant Proteins in E. coli. PLOS ONE 5(12), e15801.

Kruger, R., Kuhn, W., Muller, T., Woitalla, D., Graeber, M., Kosel, S., Przuntek, H., Epplen, J.T., Schols, L., Riess, O., 1998. Ala30Pro mutation in the gene encoding alphasynuclein in Parkinson's disease. Nat Genet 18(2), 106-108.

Lesage, S., Anheim, M., Letournel, F., Bousset, L., Honore, A., Rozas, N., Pieri, L., Madiona, K., Durr, A., Melki, R., Verny, C., Brice, A., French Parkinson's Disease Genetics Study, G., 2013. G51D alpha-synuclein mutation causes a novel parkinsonian-pyramidal syndrome. Annals of neurology 73(4), 459-471.

Lewandowski, J.R., De Paepe, G., Griffin, R.G., 2007. Proton assisted insensitive nuclei cross polarization. J Am Chem Soc 129(4), 728-729.

Lewis, A.J., Genoud, C., Pont, M., van de Berg, W.D., Frank, S., Stahlberg, H., Shahmoradian, S.H., Al-Amoudi, A., 2019. Imaging of post-mortem human brain tissue using electron and X-ray microscopy. Current opinion in structural biology 58138-148.

Li, B., Ge, P., Murray, K.A., Sheth, P., Zhang, M., Nair, G., Sawaya, M.R., Shin, W.S., Boyer, D.R., Ye, S., Eisenberg, D.S., Zhou, Z.H., Jiang, L., 2018a. Cryo-EM of fulllength $\alpha$-synuclein reveals fibril polymorphs with a common structural kernel. Nature Communications 9(1), 3609. 
Li, H.T., Du, H.N., Tang, L., Hu, J., Hu, H.Y., 2002. Structural transformation and aggregation of human alpha-synuclein in trifluoroethanol: non-amyloid component sequence is essential and beta-sheet formation is prerequisite to aggregation. Biopolymers 64(4), 221-226.

Li, W., West, N., Colla, E., Pletnikova, O., Troncoso, J.C., Marsh, L., Dawson, T.M., Jakala, P., Hartmann, T., Price, D.L., Lee, M.K., 2005. Aggregation promoting C-terminal truncation of alpha-synuclein is a normal cellular process and is enhanced by the familial Parkinson's disease-linked mutations. Proc Natl Acad Sci U S A 102(6), 2162-2167.

Li, W.W., Yang, R., Guo, J.C., Ren, H.M., Zha, X.L., Cheng, J.S., Cai, D.F., 2007. Localization of alpha-synuclein to mitochondria within midbrain of mice. Neuroreport 18(15), 1543-1546.

Li, Y., Zhao, C., Luo, F., Liu, Z., Gui, X., Luo, Z., Zhang, X., Li, D., Liu, C., Li, X., 2018b. Amyloid fibril structure of $\alpha$-synuclein determined by cryo-electron microscopy. Cell Research 28(9), 897-903.

Liu, C.W., Giasson, B.I., Lewis, K.A., Lee, V.M., Demartino, G.N., Thomas, P.J., 2005. A precipitating role for truncated alpha-synuclein and the proteasome in alpha-synuclein aggregation: implications for pathogenesis of Parkinson disease. J Biol Chem 280(24), 22670-22678.

Luk, K.C., Song, C., O'Brien, P., Stieber, A., Branch, J.R., Brunden, K.R., Trojanowski, J.Q., Lee, V.M., 2009. Exogenous alpha-synuclein fibrils seed the formation of Lewy body-like intracellular inclusions in cultured cells. Proc Natl Acad Sci U S A 106(47), 20051-20056.

Lv, G., Kumar, A., Giller, K., Orcellet, M.L., Riedel, D., Fernandez, C.O., Becker, S., Lange, A., 2012. Structural comparison of mouse and human alpha-synuclein amyloid fibrils by solid-state NMR. J Mol Biol 420(1-2), 99-111.

Mahul-Mellier, A.-L., Altay, M.F., Burtscher, J., Maharjan, N., Ait-Bouziad, N., Chiki, A., Vingill, S., Wade-Martins, R., Holton, J.L., Strand, C., Haikal, C., Li, J.-Y., Hamelin, R., Croisier, M., Knott, G., Mairet-Coello, G., Weerens, L., Michel, A., Downey, P., Citron, M., Lashuel, H.A., 2019. The making of a Lewy body: the role of alphasynuclein post-fibrillization modifications in regulating the formation and the maturation of pathological inclusions. bioRxiv500058.

Mastronarde, D.N., 2005. Automated electron microscope tomography using robust prediction of specimen movements. J Struct Biol 152(1), 36-51.

Mbefo, M.K., Fares, M.B., Paleologou, K., Oueslati, A., Yin, G., Tenreiro, S., Pinto, M., Outeiro, T., Zweckstetter, M., Masliah, E., Lashuel, H.A., 2015. Parkinson disease mutant E46K enhances alpha-synuclein phosphorylation in mammalian cell lines, in yeast, and in vivo. J Biol Chem 290(15), 9412-9427.

Meier, B.H., Böckmann, A., 2015. The structure of fibrils from 'misfolded' proteins. Current opinion in structural biology 3043-49.

Moors, T.E., Maat, C.A., Niedieker, D., Mona, D., Petersen, D., Timmermans-Huisman, E., Kole, J., El-Mashtoly, S.F., Zago, W., Barbour, R., Mundigl, O., Kaluza, K., Huber, S., Hug, M.N., Kremer, T., Ritter, M., Dziadek, S., Geurts, J.J.G., Gerwert, K., Britschgi, M., van de Berg, W.D.J., 2018. Detailed structural orchestration of Lewy pathology in Parkinson's disease as revealed by 3D multicolor STED microscopy. bioRxiv470476.

Mougenot, A.L., Nicot, S., Bencsik, A., Morignat, E., Verchere, J., Lakhdar, L., Legastelois, S., Baron, T., 2012. Prion-like acceleration of a synucleinopathy in a transgenic mouse model. Neurobiol Aging 33(9), 2225-2228. 
Nonaka, T., Iwatsubo, T., Hasegawa, M., 2005. Ubiquitination of alpha-synuclein. Biochemistry 44(1), 361-368.

Oueslati, A., Fournier, M., Lashuel, H.A., 2010. Chapter 7 - Role of post-translational modifications in modulating the structure, function and toxicity of $\alpha$-synuclein: Implications for Parkinson's disease pathogenesis and therapies, p. 115-145, in: A. Björklund and M. A. Cenci, Eds.), Progress in Brain Research, Elsevier.

Pasanen, P., Myllykangas, L., Siitonen, M., Raunio, A., Kaakkola, S., Lyytinen, J., Tienari, P.J., Poyhonen, M., Paetau, A., 2014. Novel alpha-synuclein mutation A53E associated with atypical multiple system atrophy and Parkinson's disease-type pathology. Neurobiol Aging 35(9), 2180 e2181-2185.

Peelaerts, W., Bousset, L., Van der Perren, A., Moskalyuk, A., Pulizzi, R., Giugliano, M., Van den Haute, C., Melki, R., Baekelandt, V., 2015. alpha-Synuclein strains cause distinct synucleinopathies after local and systemic administration. Nature 522(7556), 340-344.

Peng, C., Gathagan, R.J., Covell, D.J., Medellin, C., Stieber, A., Robinson, J.L., Zhang, B., Pitkin, R.M., Olufemi, M.F., Luk, K.C., Trojanowski, J.Q., Lee, V.M., 2018. Cellular milieu imparts distinct pathological alpha-synuclein strains in alphasynucleinopathies. Nature 557(7706), 558-563.

Perrin, R.J., Woods, W.S., Clayton, D.F., George, J.M., 2000. Interaction of human alphaSynuclein and Parkinson's disease variants with phospholipids. Structural analysis using site-directed mutagenesis. J Biol Chem 275(44), 34393-34398.

Polymeropoulos, M.H., Lavedan, C., Leroy, E., Ide, S.E., Dehejia, A., Dutra, A., Pike, B., Root, H., Rubenstein, J., Boyer, R., Stenroos, E.S., Chandrasekharappa, S., Athanassiadou, A., Papapetropoulos, T., Johnson, W.G., Lazzarini, A.M., Duvoisin, R.C., Di Iorio, G., Golbe, L.I., Nussbaum, R.L., 1997. Mutation in the alphasynuclein gene identified in families with Parkinson's disease. Science 276(5321), 2045-2047.

Post, M.R., Lieberman, O.J., Mosharov, E.V., 2018. Can Interactions Between $\alpha$-Synuclein, Dopamine and Calcium Explain Selective Neurodegeneration in Parkinson's Disease? Frontiers in Neuroscience 12161.

Prasad, K., Beach, T.G., Hedreen, J., Richfield, E.K., 2012. Critical role of truncated alphasynuclein and aggregates in Parkinson's disease and incidental Lewy body disease. Brain Pathol 22(6), 811-825.

Proukakis, C., Dudzik, C.G., Brier, T., MacKay, D.S., Cooper, J.M., Millhauser, G.L., Houlden, H., Schapira, A.H., 2013. A novel alpha-synuclein missense mutation in Parkinson disease. Neurology 80(11), 1062-1064.

Riek, R., 2017. The Three-Dimensional Structures of Amyloids. Cold Spring Harb Perspect Biol 9(2), a023572.

Rodriguez, J.A., Ivanova, M.I., Sawaya, M.R., Cascio, D., Reyes, F.E., Shi, D., Sangwan, S., Guenther, E.L., Johnson, L.M., Zhang, M., Jiang, L., Arbing, M.A., Nannenga, B.L., Hattne, J., Whitelegge, J., Brewster, A.S., Messerschmidt, M., Boutet, S., Sauter, N.K., Gonen, T., Eisenberg, D.S., 2015. Structure of the toxic core of alpha-synuclein from invisible crystals. Nature 525(7570), 486-490.

Scheres, S.H., 2012. RELION: implementation of a Bayesian approach to cryo-EM structure determination. Journal of Structural Biology 180(3), 519-530.

Schutz, A.K., Vagt, T., Huber, M., Ovchinnikova, O.Y., Cadalbert, R., Wall, J., Guntert, P., Böckmann, A., Glockshuber, R., Meier, B.H., 2015. Atomic-resolution threedimensional structure of amyloid beta fibrils bearing the Osaka mutation. Angew Chem Int Ed Engl 54(1), 331-335. 
Shahmoradian, S.H., Lewis, A.J., Genoud, C., Hench, J., Moors, T.E., Navarro, P.P., Castano-Diez, D., Schweighauser, G., Graff-Meyer, A., Goldie, K.N., Sutterlin, R., Huisman, E., Ingrassia, A., Gier, Y., Rozemuller, A.J.M., Wang, J., Paepe, A., Erny, J., Staempfli, A., Hoernschemeyer, J., Grosseruschkamp, F., Niedieker, D., ElMashtoly, S.F., Quadri, M., Van, I.W.F.J., Bonifati, V., Gerwert, K., Bohrmann, B., Frank, S., Britschgi, M., Stahlberg, H., Van de Berg, W.D.J., Lauer, M.E., 2019. Lewy pathology in Parkinson's disease consists of crowded organelles and lipid membranes. Nature neuroscience 22(7), 1099-1109.

Singleton, A.B., Farrer, M., Johnson, J., Singleton, A., Hague, S., Kachergus, J., Hulihan, M., Peuralinna, T., Dutra, A., Nussbaum, R., Lincoln, S., Crawley, A., Hanson, M., Maraganore, D., Adler, C., Cookson, M.R., Muenter, M., Baptista, M., Miller, D., Blancato, J., Hardy, J., Gwinn-Hardy, K., 2003. alpha-Synuclein locus triplication causes Parkinson's disease. Science 302(5646), 841.

Spillantini, M.G., Crowther, R.A., Jakes, R., Hasegawa, M., Goedert, M., 1998a. $\alpha$-Synuclein in filamentous inclusions of Lewy bodies from Parkinson's disease and dementia with Lewy bodies. Proceedings of the National Academy of Sciences 95(11), 6469-6473.

Spillantini, M.G., Schmidt, M.L., Lee, V.M., Trojanowski, J.Q., Jakes, R., Goedert, M., 1997. Alpha-synuclein in Lewy bodies. Nature 388(6645), 839-840.

Spillantini, M.G., Crowther, R.A., Jakes, R., Cairns, N.J., Lantos, P.L., Goedert, M., 1998b. Filamentous alpha-synuclein inclusions link multiple system atrophy with Parkinson's disease and dementia with Lewy bodies. Neuroscience letters 251(3), 205-208.

Stefanis, L., 2012. alpha-Synuclein in Parkinson's disease. Cold Spring Harb Perspect Med 2(2), a009399.

Tuttle, M.D., Comellas, G., Nieuwkoop, A.J., Covell, D.J., Berthold, D.A., Kloepper, K.D., Courtney, J.M., Kim, J.K., Barclay, A.M., Kendall, A., Wan, W., Stubbs, G., Schwieters, C.D., Lee, V.M., George, J.M., Rienstra, C.M., 2016. Solid-state NMR structure of a pathogenic fibril of full-length human alpha-synuclein. Nat Struct Mol Biol 23(5), 409-415.

Ueda, K., Fukushima, H., Masliah, E., Xia, Y., Iwai, A., Yoshimoto, M., Otero, D.A., Kondo, J., Ihara, Y., Saitoh, T., 1993. Molecular cloning of cDNA encoding an unrecognized component of amyloid in Alzheimer disease. Proc Natl Acad Sci U S A 90(23), 11282-11286.

Verasdonck, J., Bousset, L., Gath, J., Melki, R., Böckmann, A., Meier, B.H., 2016. Further exploration of the conformational space of alpha-synuclein fibrils: solid-state NMR assignment of a high-pH polymorph. Biomol NMR Assign 10(1), 5-12.

Vilar, M., Chou, H.T., Luhrs, T., Maji, S.K., Riek-Loher, D., Verel, R., Manning, G., Stahlberg, H., Riek, R., 2008. The fold of alpha-synuclein fibrils. Proc Natl Acad Sci U S A 105(25), 8637-8642.

Walti, M.A., Ravotti, F., Arai, H., Glabe, C.G., Wall, J.S., Böckmann, A., Guntert, P., Meier, B.H., Riek, R., 2016. Atomic-resolution structure of a disease-relevant Abeta(1-42) amyloid fibril. Proc Natl Acad Sci U S A 113(34), E4976-4984.

Wang, W., Nguyen, L.T.T., Burlak, C., Chegini, F., Guo, F., Chataway, T., Ju, S., Fisher, O.S., Miller, D.W., Datta, D., Wu, F., Wu, C.-X., Landeru, A., Wells, J.A., Cookson, M.R., Boxer, M.B., Thomas, C.J., Gai, W.P., Ringe, D., Petsko, G.A., Hoang, Q.Q., 2016. Caspase-1 causes truncation and aggregation of the Parkinson's diseaseassociated protein $\alpha$-synuclein. Proceedings of the National Academy of Sciences 113(34), 9587-9592.

Williams, C.J., Headd, J.J., Moriarty, N.W., Prisant, M.G., Videau, L.L., Deis, L.N., Verma, V., Keedy, D.A., Hintze, B.J., Chen, V.B., Jain, S., Lewis, S.M., Arendall, W.B., 3rd, 
Snoeyink, J., Adams, P.D., Lovell, S.C., Richardson, J.S., Richardson, D.C., 2018. MolProbity: More and better reference data for improved all-atom structure validation. Protein Sci 27(1), 293-315.

Zarranz, J.J., Alegre, J., Gomez-Esteban, J.C., Lezcano, E., Ros, R., Ampuero, I., Vidal, L., Hoenicka, J., Rodriguez, O., Atares, B., Llorens, V., Gomez Tortosa, E., del Ser, T., Munoz, D.G., de Yebenes, J.G., 2004. The new mutation, E46K, of alpha-synuclein causes Parkinson and Lewy body dementia. Annals of neurology 55(2), 164-173.

Zhang, W., Falcon, B., Murzin, A.G., Fan, J., Crowther, R.A., Goedert, M., Scheres, S.H., 2019. Heparin-induced tau filaments are polymorphic and differ from those in Alzheimer's and Pick's diseases. Elife 8(e43584).

Zheng, S.Q., Palovcak, E., Armache, J.P., Verba, K.A., Cheng, Y., Agard, D.A., 2017. MotionCor2: anisotropic correction of beam-induced motion for improved cryoelectron microscopy. Nat Methods 14(4), 331-332.

Zivanov, J., Nakane, T., Forsberg, B.O., Kimanius, D., Hagen, W.J., Lindahl, E., Scheres, S.H., 2018. New tools for automated high-resolution cryo-EM structure determination in RELION-3. Elife 7(e42166). 